\title{
Idades U-Pb em zircão do conglomerado diamantífero de Grão Mogol (Supergrupo Espinhaço): implicações para a origem dos diamantes da Serra do Espinhaço em Minas Gerais
}

\author{
$\mathrm{U}-\mathrm{Pb}$ ages in zircon of the Grão Mogol diamond-bearing \\ conglomerate (Espinhaço Supergroup): implications for the \\ diamond origin in the Espinhaço Range in Minas Gerais \\ Mario Luiz de Sá Carneiro Chaves ${ }^{1 *}$, Marly Babinski², \\ Márcio Célio Rodrigues da Silva ${ }^{3}$, Ricardo Scholz ${ }^{4}$
}

RESUMO: A Serra do Espinhaço na regiāo de Grão Mogol, centro-norte de Minas Gerais, é constituída de quartzitos finos com estratificaçóes cruzadas de grande porte (Formaçáo Resplandecente), os quais são sobrepostos em discordância erosiva marcante por conglomerados monomíticos e quartzitos médios a grossos (Formaçáo Grão Mogol), ambos unidades pertencentes ao Supergrupo Espinhaço, de idade proterozoica. Na localidade conhecida como "Pedra Rica", um antigo garimpo de diamantes, rochas dessas formaçôes foram amostradas, e delas separados zircốes detríticos para dataçôes U-Pb por Espectrometria de massa de ionização por plasma com ablação a laser (LA-ICPMS). Os grãos analisados são arredondados a subarredondados e, em sua maioria, mostram zoneamento oscilatório. Os resultados obtidos identificaram, para a Formaçấo Resplandecente, idade máxima de deposição de $1.595 \pm 20 \mathrm{Ma}$, e para a Formação Gráo Mogol de $1.052 \pm 50 \mathrm{Ma}$. A comparaçâo entre os dados adquiridos e dataçóes disponíveis para a região de Diamantina e adjacências, na mesma província diamantífera, constitui forte indicativo da possibilidade de existência de pelo menos 2 eventos primários mineralizantes na bacia, no intervalo de idades de 1,35 a 1,05 Ga.

PALAVRAS-CHAVE: idades U-Pb; Conglomerado Grão Mogol; diamante.
ABSTRACT: The Espinhaço Range in the Gräo Mogol region, center-north of Minas Gerais state, is composed by fine grained quartzites with large cross stratifications (Resplandecente Formation), which are covered with erosional unconformity by monomictic conglomerates, and medium to coarse grained quartzites (Gräo Mogol Formation), both units belonging to the Espinhaço Supergroup, of Proterozoic age. At the locality known as "Pedra Rica" (signify Rich Rock, an old diamond digging), rocks of these formations were sampled and separated detrital zircons to acquire $U-P b$ by Laser Ablation Inductively LA-ICPMS) ages. The analyzed grains are rounded to slightly rounded and show oscillatory zoning. The obtained results indicate a maximum depositional age of 1,595 \pm 20 Ma for the Resplandecente Formation, and 1,052 $\pm 50 \mathrm{Ma}$ for the Grão Mogol Formation. The comparison between the obtained data and the available ages for the Diamantina region and proximities, in the same diamond province, indicates a strong evidence for the existence of at least two primary mineralizing events in the basin, in the age range of 1.35 to $1.05 \mathrm{Ga}$.

KEYWORDS: U-Pb ages; Grão Mogol Conglomerate; Diamond.

${ }^{1}$ Instituto de Geociências, Centro de Pesquisa Prof. Manoel Teixeira da Costa, Campus da Pampulha, Universidade Federal de Minas Gerais - IGC-UFMG, Belo Horizonte (MG), Brasil; Pesquisador CNPq.E-mail:mchaves@ufmg.br

2Instituto de Geociências, Universidade de São Paulo - USP, São Paulo (SP), Brasil; Pesquisador CNPq. E-mail: babinski@usp.br

${ }^{3}$ Programa de Pós-Graduação em Geologia, Instituto de Geociências, Centro de Pesquisa Prof. Manoel Teixeira da Costa, Campus da Pampulha, Universidade Federal de Minas Gerais - IGC-UFMG, Belo Horizonte (MG), Brasil; Geomil Ltda, Belo Horizonte (MG), Brasil. E-mail: celiogeo@gmail.com

${ }^{4}$ Departamento de Geologia, Escola de Minas, Campus Morro do Cruzeiro, Universidade Federal de Ouro Preto - UFOP, Ouro Preto (MG), Brasil. E-mail:r_scholz_br@yahoo.com *Autor correspondente

Manuscrito ID 28486. Recebido em: 14/08/2012. Aprovado em: 21/01/2013 


\section{INTRODUÇÃO}

Os diamantes encontrados na regiáo da Serra do Espinhaço, em Minas Gerais, têm sido alvos de centenas de estudos durante mais de 200 anos, e sua possível origem primária constitui a temática de intensas controvérsias. Nessa região, as rochas portadoras de diamantes mais antigas são metassedimentos relacionados às formaçóes SopaBrumadinho, nos arredores das cidades de Diamantina (Espinhaço Meridional) e Grão Mogol, na cidade homônima (Espinhaço Central), do Supergrupo Espinhaço.

Estudos estratigráficos e sedimentológicos recentes proporcionaram consideráveis avanços a respeito dos ambientes deposicionais do Supergrupo Espinhaço em escala regional (Almeida-Abreu 1993, Martins-Neto 1998, 2000, Martins-Neto et al. 2001, Uhlein \& Chaves 2001, Almeida-Abreu \& Renger 2007, Alkmim \& Martins-Neto 2012). Paralelamente, a geocronologia U/Pb de zircóes detríticos se tornou ferramenta auxiliar importante na definição da idade das rochas hospedeiras secundárias dos diamantes e, por conseguinte, possibilitando inferiçóes sobre a idade da desconhecida fonte primária da mineralização.

Os conglomerados que afloram nos arredores de Grão Mogol se revestem ainda da maior importância histórica, pois foi nessa área em que pela primeira vez em todo mundo foram encontrados diamantes encravados numa rocha (Helmreichen 1846, Chaves et al. 2009). Os estudos estratigráficos desenvolvidos por Chaves et al. (1999) demonstraram que o conglomerado Grão Mogol ocorre de maneira discordante, acima dos quartzitos da Formaçáo Resplandecente, unidade equivalente da Formação Galho do Miguel da região de Diamantina.

$\mathrm{Na}$ mesma linha de estudos bastante recentes, os quais indicaram idade muito mais nova para a Formação SopaBrumadinho do que antes admitida (Chemale Jr. et al. 2011, 2012), tornou-se também necessária uma definição da idade de deposição da Formação Grão Mogol. O presente trabalho tem como objetivo trazer essas informaçóes, a partir da datação de zircôes detríticos recuperados diretamente da "Pedra Rica", localidade tipo do conglomerado diamantífero de Grão Mogol, bem como de sua unidade inferior.

\section{Síntese geológica regional}

A Serra do Espinhaço constitui uma extensa faixa linear sul-norte, que inicia na porção central de Minas Gerais, prolongando-se para norte até a região fronteiriça Bahia/Piauí (Fig. 1). Neste contexto, são definidos diversos domínios geográficos e geotectônicos, designados de Espinhaço Meridional (MG), Espinhaço Central (MG/BA), Espinhaço Setentrional (BA/PI) e
Chapada Diamantina (BA). O espigão serrano na maior parte é sustentado pelo Supergrupo Espinhaço, formado por metassedimentos siliciclásticos (quartzitos, filitos e conglomerados), com intercalaçóes locais de rochas vulcânicas (na base) e carbonáticas (no topo). Os diamantes do Espinhaço, preferencialmente recuperados em aluvióes, se relacionam a rochas conglomeráticas proterozoicas, associadas no Espinhaço Meridional à Formação Sopa-Brumadinho, na região de Grão Mogol (Espinhaço Central) à Formação Grão Mogol, e na Chapada Diamantina à Formação Tombador, constituindo a Província Diamantífera Serra do Espinhaço.

O Espinhaço Central tem seu limite sul no anticlinório de Itacambira (Karfunkel \& Karfunkel 1976), estendendose para norte até a serra mudar de contexto geotectônico ao ingressar no domínio do Cráton São Francisco, onde vai constituir o Espinhaço Setentrional (Schobbenhaus 1993, 1996, Chaves 1997; Fig. 1). O conhecimento geológico sobre o Espinhaço Central é ainda escasso, com estudos

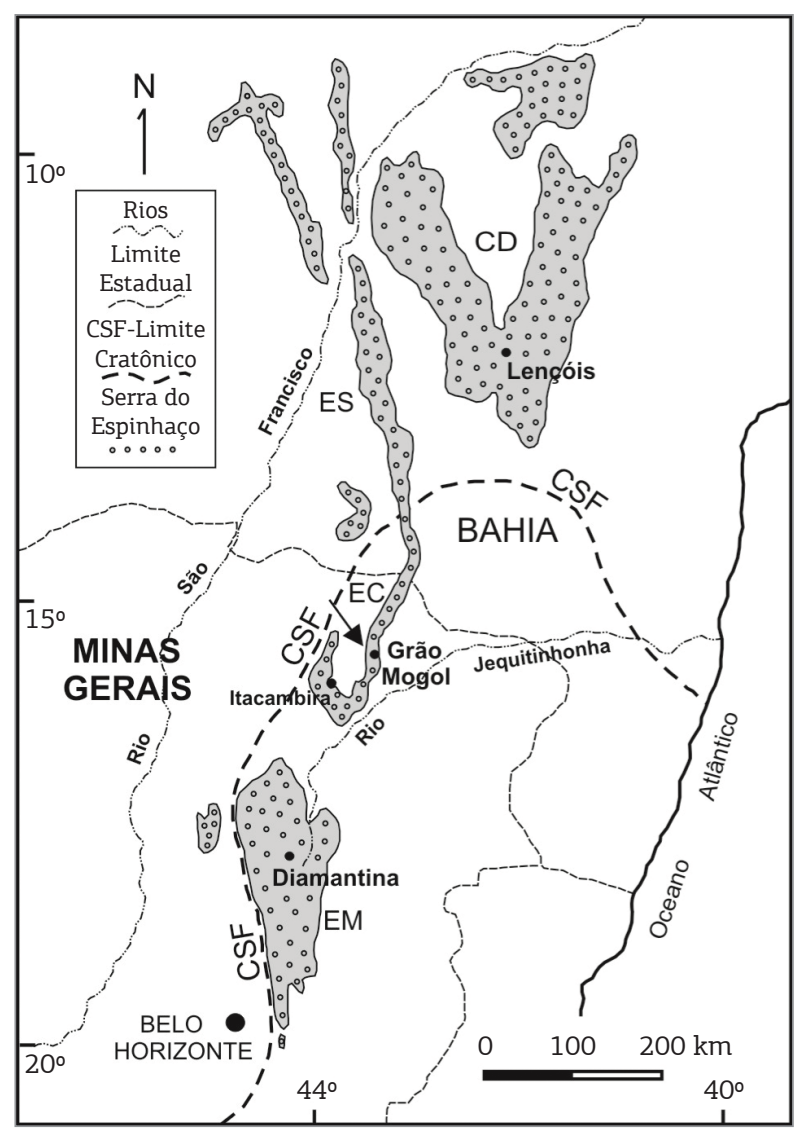

Figura 1. Distribuição regional da Serra do Espinhaço, onde prevalecem litotipos do Supergrupo Espinhaço, ao longo dos estados de Minas Gerais e Bahia. A seta realça a localidade das datações efetuadas. Domínios geotectônicos da serra: Espinhaço Meridional, Espinhaço Central, Espinhaço Setentrional e Chapada Diamantina. 
concentrados nos arredores de Itacambira (Karfunkel \& Karfunkel 1976, 1977, Martins et al. 2008) e de Grão Mogol (Chaves 1997, Chaves et al. 1999, 2009), os primeiros de cunho estratigráfico e os últimos relacionados aos depósitos diamantíferos regionais. Em Grão Mogol, o Supergrupo Espinhaço foi considerado indiviso em trabalhos de menor escala (Heineck et al. 2003), embora estudos mais detalhados reconhecessem duas unidades separadas por um importante hiato deposicional, designadas formaçôes Resplandecente e Grão Mogol (Chaves 1997, Chaves et al. 1999).

A Formação Resplandecente é constituída de quartzitos finos, com estratos cruzados de grande porte generalizados, de origem eólica, possuindo 250 a $300 \mathrm{~m}$ de espessura, enquanto a Formação Gráo Mogol a recobre de maneira possivelmente discordante (Fig. 2), representada por conglomerados basais, aluviais, que são sobrepostos por quartzitos médios a grossos, de espessura total próxima de $80 \mathrm{~m}$ (o membro basal não ultrapassa $10 \mathrm{~m}$ ). Nesse

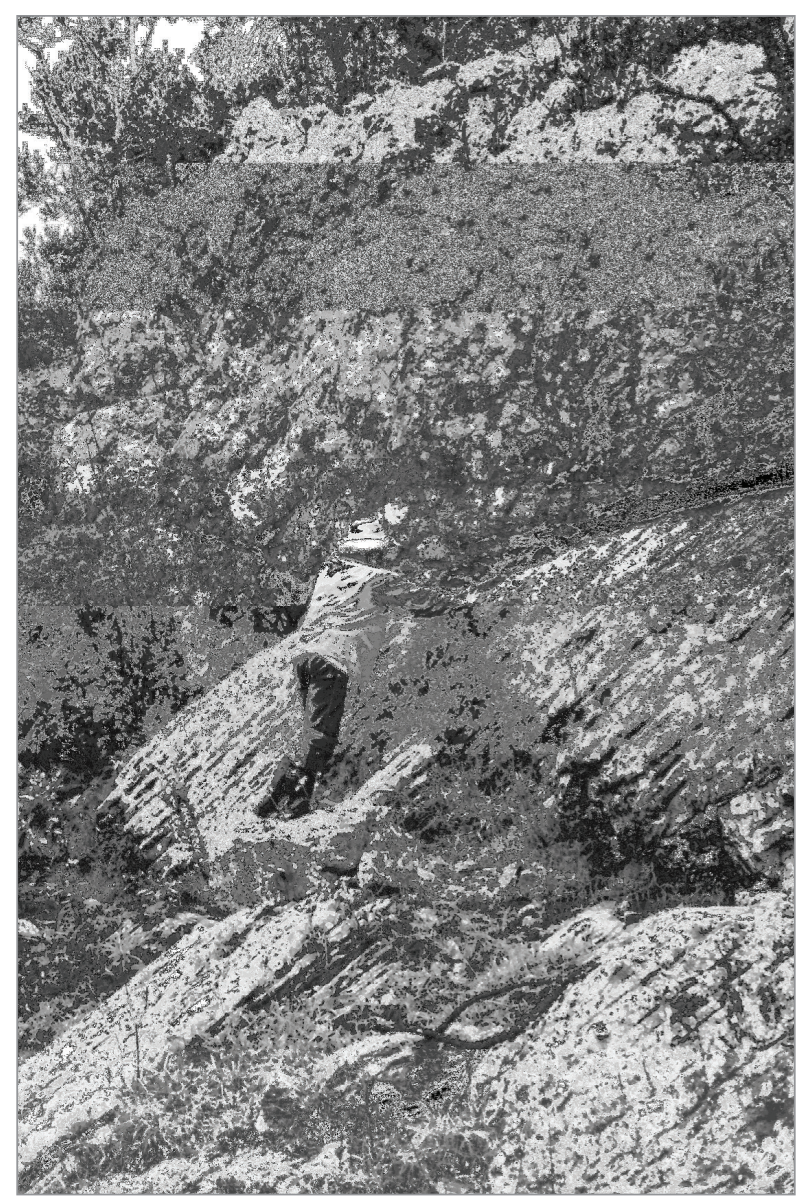

Figura 2. Contato discordante possivelmente erosional entre os metarenitos eólicos da Formação Resplandecente, com sets cruzados de alto ângulo, sobrepostos pelos conglomerados da Formação Grão Mogol. modelo, proposto por Chaves (1997) e Chaves et al. (1999), foi traçado um paralelo entre os metarenitos das formaçōes Galho do Miguel (Espinhaço Meridional) e Resplandecente (Espinhaço Central), e, assim, a unidade portadora de diamantes (Formação Grão Mogol) estaria isolada em termos estratigráficos sobre a anterior (Fig. 3A). O Morro da Pedra Rica, local da coleta das amostras analisadas, é uma das principais áreas onde a porção de base da Formação Grão Mogol é reconhecida. Tal arranjo se contrapóe ao sugerido por Karfunkel \& Karfunkel $(1976,1977)$ para a região de Itacambira, próxima, no qual as sequências do Supergrupo Espinhaço nas regióes meridional e central foram relacionadas por meio da ligaçấo entre as unidades diamantíferas Sopa-Brumadinho e Água Preta (Fig. 3B).

O Supergrupo Espinhaço em seu domínio Meridional foi depositado em uma bacia do tipo rifte-sag, na seçâo basal, que evoluiu para uma bacia flexural de margem passiva, em sua porção superior (Martins-Neto 1998, 2000, Martins Neto et al. 2001). A parte inferior, no Espinhaço Meridional foi reunida no Grupo Diamantina, e a superior no Grupo Conselheiro Mata (Dossin et al. 1990). Na região de Grão Mogol é provável que somente a porção superior do Grupo Diamantina esteja presente. Rochas metavulcânicas da base do Supergrupo Espinhaço foram datadas no final do Paleoproterozoico, entre 1,77 Ga e 1,71 Ga (Brito-Neves et al. 1979, Machado et al. 1989, Dussin 1994). Um hiato deposicional expressivo foi reconhecido recentemente entre as formaçôes São João da Chapada e Sopa-Brumadinho, pela identificaçáo de zircóes detríticos com cerca de 1,08 Ga nesta última (Chemale Jr. et al. 2011, 2012), embora a baixa quantidade de dados ora disponíveis ainda não permita extrapolaçôes a respeito da evoluçáo da bacia como um todo. O Supergrupo Espinhaço foi deformado e metamorfizado sob condiçôes de fácies xisto verde baixo durante o evento orogenético Brasiliano, no Neoproterozoico (Uhlein 1991, Schobbenhaus 1993, 1996).

\section{Procedimentos analíticos}

As amostras foram preparadas pelo método tradicional, em que aproximadamente $10 \mathrm{~kg}$ de cada foram cominuídos em britador de mandíbula e sofreu moagem em moinho de panela no do Departamento de Geologia da Universidade Federal de Ouro Preto. Os minerais pesados foram concentrados por bateiamento manual, e os magnéticos separados da fração rica em zircôes com a utilização de imã de mão. Posteriormente, foram utilizados líquidos densos como o diiodometano e o bromofórmio, para separação de quartzo residual e alguns minerais pesados indesejados.

Os zircóes recuperados foram analisados no Centro de Pesquisas Geocronológicas da Universidade de São Paulo 
(USP), onde inicialmente foram obtidas imagens de catodoluminescência no microscópio eletrônico de varredura, marca Quanta 250. Após montadas em resina e polidas, as análises isotópicas $\mathrm{U}-\mathrm{Pb}$ foram realizadas utilizando o equipamento ICP-MS Neptune, com multicoletores, acoplado a um laser tipo Photon 193. Os diagramas de concórdia e os histogramas de frequência se basearam no Programa Isoplot (Ludwig 2001).

\section{Dados obtidos}

A amostra de quartzito fino da Formação Resplandecente forneceu zircôes arredondados a subarredondados, com tamanhos variando entre 90 e $220 \mu \mathrm{m}$. Os cristais mostram zoneamento oscilatório, típico de uma origem ígnea. Os zircóes recuperados da matriz do conglomerado da Formação Grão Mogol são abundantes e, igualmente, possuem zoneamento oscilatório e se apresentam arredondados a subarredondados, embora sejam menores, com tamanho variando entre 75 e $150 \mu \mathrm{m}$.

Os 87 pontos analisados em 84 grãos do quartzito basal apresentaram idades $\mathrm{U}-\mathrm{Pb}$ variando entre 1.595 e $3.535 \mathrm{Ma}$, sendo que 57 deles ocorrem em um intervalo principal de idades concentrado entre 1,98 a $2,20 \mathrm{Ga}(-65 \%$ da população), sugerindo que essas são as idades das rochas fontes

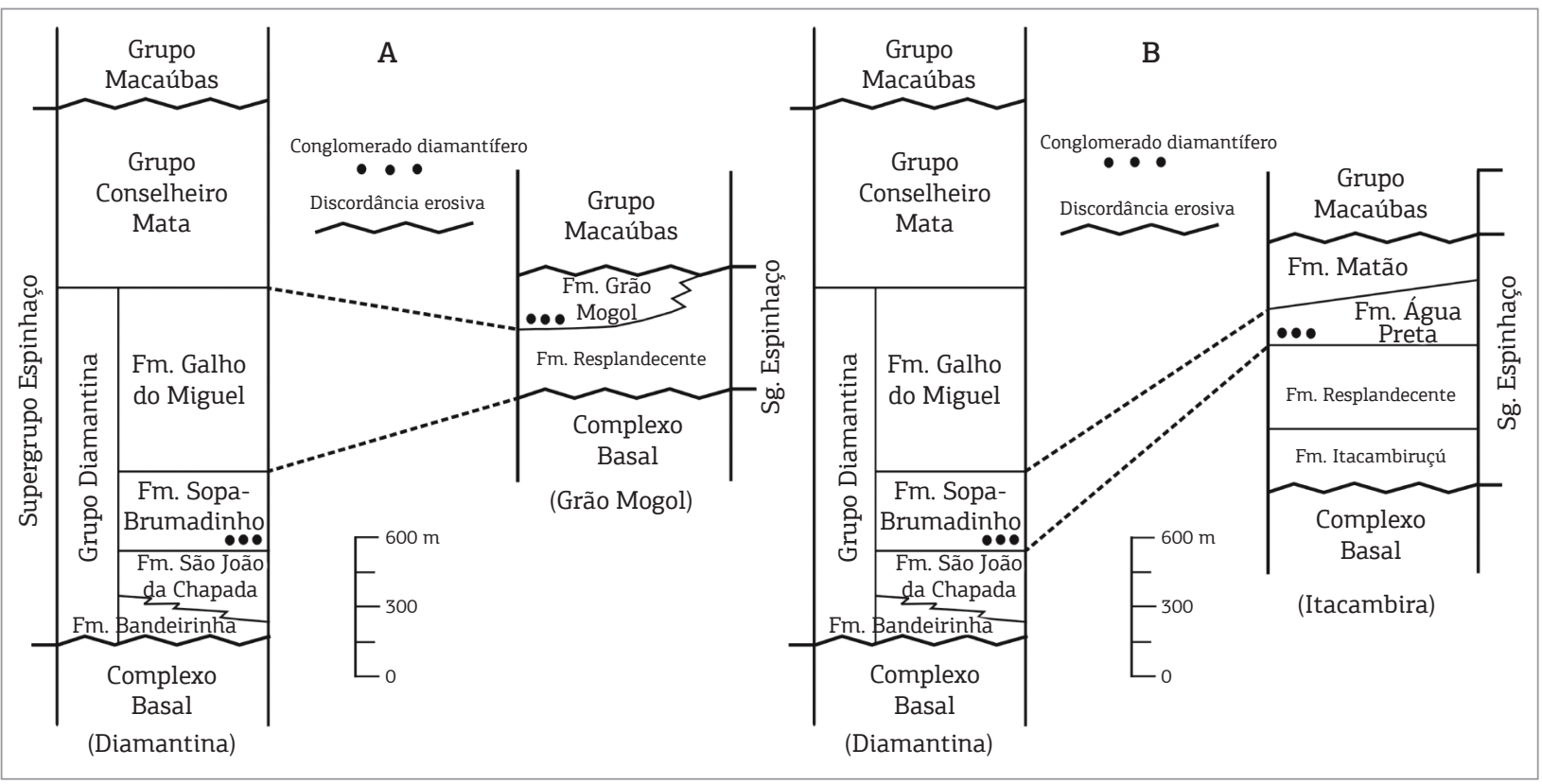

Figura 3. Coluna estratigráfica esquemática e sintetizada do Supergrupo Espinhaço na região de Diamantina (Schöll \& Fogaça 1979, Dossin et al. 1990, Almeida-Abreu 1993), comparando-se com (A) a correlação proposta para a região de Itacambira (Karfunkel \& Karfunkel 1976, 1977) e (B) para a região de Grão Mogol (Chaves 1997, Chaves et al. 1999).

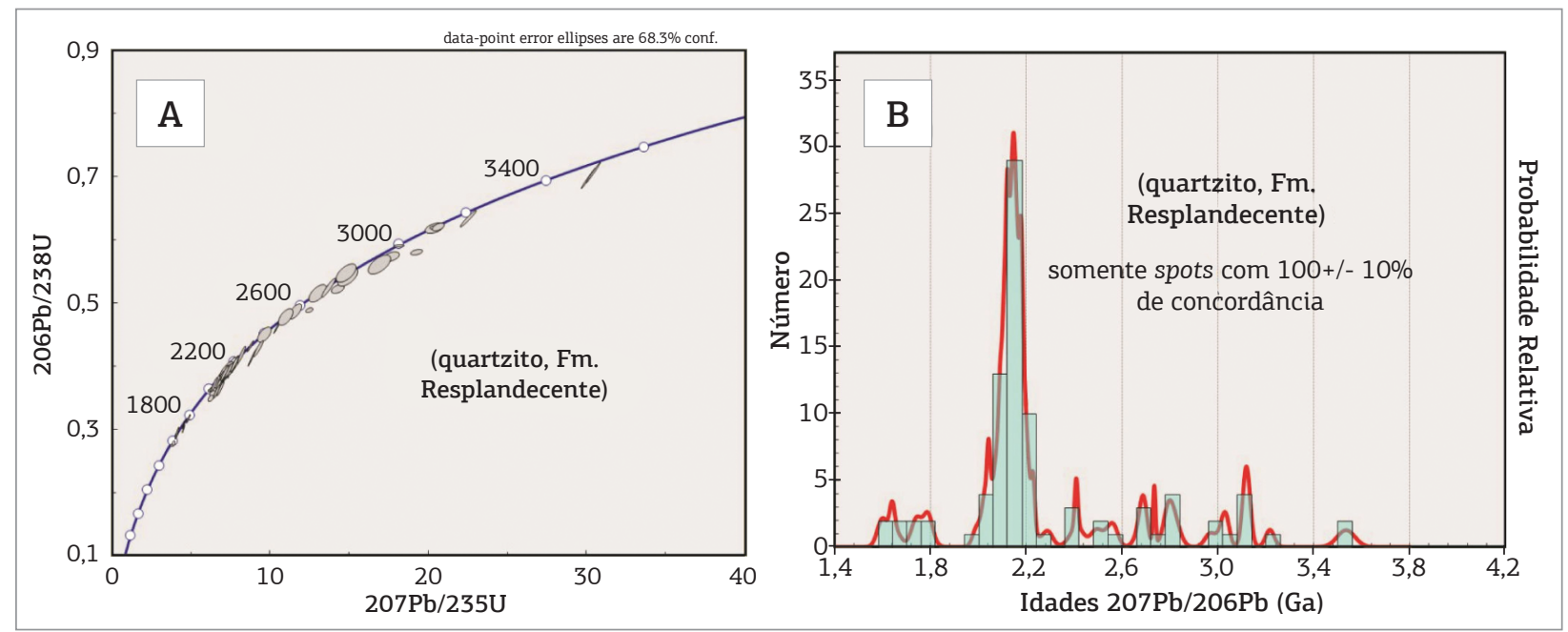

Figura 4. Diagrama U-Pb concórdia (A) e histograma de probabilidade relativa (B) dos zircões detríticos amostrados no quartzito da Formação Resplandecente. 
Mario Luiz de Sá Carneiro Chaves et al.

Tabela 1. Dados geocronológicos U-Pb obtidos em zircões detríticos do quartzito da Formação Resplandecente em Grão Mogol, Espinhaço Meridional

\begin{tabular}{|c|c|c|c|c|c|c|c|c|c|c|c|c|}
\hline \multirow[b]{2}{*}{ Ponto } & \multicolumn{5}{|c|}{ Razões isotópicas } & \multicolumn{6}{|c|}{ Idades (Ma) } & \multirow[b]{2}{*}{ Concord. } \\
\hline & $\begin{array}{c}207 / \\
235\end{array}$ & $\begin{array}{c}\text { Erro } \\
1 \Sigma\end{array}$ & $\begin{array}{c}206 / \\
238\end{array}$ & $\begin{array}{c}\text { Erro } \\
1 \Sigma\end{array}$ & $\begin{array}{l}\text { Erro } \\
\text { Corr. }\end{array}$ & $\begin{array}{c}\text { T206/ } \\
238\end{array}$ & $\begin{array}{c}\text { Erro } \\
1 \Sigma\end{array}$ & $\begin{array}{c}\text { T207/ } \\
235\end{array}$ & $\begin{array}{c}\text { Erro } \\
1 \Sigma\end{array}$ & $\begin{array}{c}\text { T207/ } \\
206\end{array}$ & $\begin{array}{c}\text { Erro } \\
1 \Sigma\end{array}$ & \\
\hline 1,1 & 7,8494 & 0,0906 & 0,4081 & 0,0067 & 0,99 & 2206 & 0,031 & 2214 & 0,010 & 2208 & 0,039 & 100 \\
\hline 2,1 & 7,0325 & 0,0686 & 0,3844 & 0,0059 & 0,99 & 2097 & 0,028 & 2116 & 0,009 & 2126 & 0,039 & 99 \\
\hline 2,2 & 6,9367 & 0,0680 & 0,3799 & 0,0059 & 0,99 & 2076 & 0,027 & 2103 & 0,009 & 2129 & 0,039 & 98 \\
\hline 3,1 & 7,0587 & 0,0754 & 0,3895 & 0,0061 & 0,99 & 2121 & 0,028 & 2119 & 0,009 & 2145 & 0,039 & 99 \\
\hline 4,1 & 7,0756 & 0,0706 & 0,3836 & 0,0060 & 0,99 & 2093 & 0,028 & 2121 & 0,009 & 2147 & 0,038 & 98 \\
\hline 5,1 & 6,7038 & 0,0649 & 0,3778 & 0,0058 & 0,99 & 2066 & 0,027 & 2073 & 0,009 & 2076 & 0,038 & 100 \\
\hline 6,1 & 30,0957 & 0,2928 & 0,6996 & 0,0108 & 0,99 & 3419 & 0,041 & 3490 & 0,010 & 3533 & 0,037 & 97 \\
\hline 6,2 & 30,3966 & 0,2936 & 0,7079 & 0,0110 & 0,99 & 3450 & 0,041 & 3500 & 0,009 & 3535 & 0,037 & 98 \\
\hline 7,1 & 7,0396 & 0,0684 & 0,3866 & 0,0060 & 0,99 & 2107 & 0,028 & 2116 & 0,009 & 2130 & 0,038 & 99 \\
\hline 7,2 & 6,8319 & 0,0661 & 0,3734 & 0,0058 & 0,99 & 2045 & 0,027 & 2090 & 0,009 & 2138 & 0,038 & 96 \\
\hline 8,1 & 8,8262 & 0,1722 & 0,4154 & 0,0088 & 0,99 & 2240 & 0,040 & 2320 & 0,018 & 2413 & 0,039 & 93 \\
\hline 9,1 & 7,4175 & 0,0726 & 0,3922 & 0,0062 & 0,99 & 2133 & 0,028 & 2163 & 0,009 & 2189 & 0,038 & 97 \\
\hline 10,1 & 6,9787 & 0,0677 & 0,3794 & 0,0059 & 0,99 & 2073 & 0,028 & 2109 & 0,009 & 2148 & 0,038 & 97 \\
\hline 11,1 & 6,3214 & 0,1214 & 0,3585 & 0,0031 & 0,45 & 1975 & 0,015 & 2021 & 0,017 & 2067 & 0,018 & 96 \\
\hline 12,1 & 6,7717 & 0,1296 & 0,3737 & 0,0032 & 0,45 & 2047 & 0,015 & 2082 & 0,017 & 2119 & 0,018 & 97 \\
\hline 13,1 & 3,8520 & 0,0763 & 0,2795 & 0,0026 & 0,47 & 1589 & 0,013 & 1604 & 0,016 & 1607 & 0,022 & 99 \\
\hline 14,1 & 17,6256 & 0,3518 & 0,5746 & 0,0049 & 0,43 & 2927 & 0,020 & 2970 & 0,019 & 3020 & 0,019 & 97 \\
\hline 15,1 & 7,2826 & 0,1389 & 0,3944 & 0,0034 & 0,45 & 2143 & 0,016 & 2147 & 0,017 & 2153 & 0,018 & 100 \\
\hline 16,1 & 7,0896 & 0,1350 & 0,3853 & 0,0033 & 0,45 & 2101 & 0,015 & 2123 & 0,017 & 2151 & 0,018 & 98 \\
\hline 17,1 & 7,1166 & 0,1361 & 0,3896 & 0,0035 & 0,46 & 2121 & 0,016 & 2126 & 0,017 & 2115 & 0,018 & 100 \\
\hline 18,1 & 6,2152 & 0,1217 & 0,3506 & 0,0035 & 0,51 & 1937 & 0,017 & 2007 & 0,017 & 2087 & 0,018 & 93 \\
\hline 19,1 & 7,0767 & 0,1342 & 0,3845 & 0,0033 & 0,46 & 2097 & 0,015 & 2121 & 0,017 & 2146 & 0,018 & 98 \\
\hline 20,1 & 20,3234 & 0,3830 & 0,6200 & 0,0053 & 0,45 & 3110 & 0,021 & 3107 & 0,018 & 3116 & 0,016 & 100 \\
\hline 21,1 & 7,2188 & 0,1362 & 0,3922 & 0,0034 & 0,46 & 2133 & 0,016 & 2139 & 0,017 & 2144 & 0,018 & 100 \\
\hline 22,1 & 14,2688 & 0,2706 & 0,5238 & 0,0044 & 0,45 & 2715 & 0,019 & 2768 & 0,018 & 2792 & 0,017 & 97 \\
\hline 23,1 & \begin{tabular}{|l|}
7,3655 \\
\end{tabular} & 0,1383 & 0,3979 & 0,0034 & 0,46 & 2160 & 0,016 & 2157 & 0,017 & 2153 & 0,018 & 100 \\
\hline 24,1 & 3,7475 & 0,0462 & 0,2766 & 0,0011 & 0,31 & 1574 & 0,005 & 1582 & 0,010 & 1595 & 0,020 & 99 \\
\hline 25,1 & 19,2400 & 0,2322 & 0,5822 & 0,0030 & 0,43 & 2958 & 0,012 & 3054 & 0,012 & 3126 & 0,015 & 95 \\
\hline 26,1 & \begin{tabular}{|l|}
7,5229 \\
\end{tabular} & 0,0840 & 0,4000 & 0,0012 & 0,28 & 2169 & 0,006 & 2176 & 0,010 & 2179 & 0,016 & 100 \\
\hline 27,1 & 12,7886 & 0,1448 & 0,5088 & 0,0015 & 0,27 & 2651 & 0,007 & 2664 & 0,011 & 2684 & 0,016 & 99 \\
\hline 28,1 & 20,4174 & 0,2290 & 0,6206 & 0,0020 & 0,28 & 3112 & 0,008 & 3111 & 0,011 & 3117 & 0,015 & 100 \\
\hline 28,2 & 20,6124 & 0,2579 & 0,6218 & 0,0041 & 0,53 & 3117 & 0,016 & 3121 & 0,012 & 3115 & 0,015 & 100 \\
\hline 29,1 & 6,1979 & 0,0751 & 0,3639 & 0,0018 & 0,41 & 2001 & 0,009 & 2004 & 0,011 & 1993 & 0,017 & 100 \\
\hline 30,1 & 4,7328 & 0,0537 & 0,3181 & 0,0010 & 0,28 & 1780 & 0,005 & 1773 & 0,009 & 1789 & 0,017 & 100 \\
\hline 31,1 & 7,0639 & 0,0773 & 0,3833 & 0,0008 & 0,19 & 2092 & 0,004 & 2120 & 0,010 & 2144 & 0,016 & 98 \\
\hline 32,1 & 7,0199 & 0,0824 & 0,3860 & 0,0014 & 0,31 & 2104 & 0,006 & 2114 & 0,010 & 2154 & 0,017 & 98 \\
\hline 33,1 & 7,5332 & 0,0941 & 0,3961 & 0,0019 & 0,38 & 2151 & 0,009 & 2177 & 0,011 & 2203 & 0,018 & 98 \\
\hline 34,1 & 18,1009 & 0,2047 & 0,5924 & 0,0015 & 0,22 & 2999 & 0,006 & 2995 & 0,011 & 3033 & 0,015 & 99 \\
\hline 35,1 & 6,6722 & 0,0738 & 0,3640 & 0,0010 & 0,25 & 2001 & 0,005 & 2069 & 0,010 & 2140 & 0,016 & 94 \\
\hline 36,1 & 14,7759 & 0,2129 & 0,5460 & 0,0075 & 0,96 & 2808 & 0,031 & 2801 & 0,014 & 2811 & 0,020 & 100 \\
\hline 37,1 & 7,5861 & 0,1091 & 0,4033 & 0,0056 & 0,97 & 2184 & 0,026 & 2183 & 0,013 & 2189 & 0,021 & 100 \\
\hline 38,1 & 7,1047 & 0,1038 & 0,3900 & 0,0055 & 0,96 & 2123 & 0,025 & 2125 & 0,013 & 2128 & 0,021 & 100 \\
\hline 39,1 & 4,7895 & 0,0717 & 0,3192 & 0,0045 & 0,94 & 1786 & 0,022 & 1783 & 0,013 & 1794 & 0,022 & 100 \\
\hline 40,1 & 4,1544 & 0,0600 & 0,2962 & 0,0041 & 0,97 & 1672 & 0,021 & 1665 & 0,012 & 1658 & 0,022 & 101 \\
\hline 41,1 & 6,9214 & 0,1096 & 0,3848 & 0,0060 & 0,98 & 2099 & 0,028 & 2101 & 0,014 & 2090 & 0,021 & 100 \\
\hline 42,1 & 8,7241 & 0,1256 & 0,4330 & 0,0060 & 0,97 & 2319 & 0,027 & 2310 & 0,013 & 2290 & 0,021 & 101 \\
\hline 43,1 & 22,5020 & 0,3258 & 0,6354 & 0,0089 & 0,97 & 3171 & 0,035 & 3206 & 0,014 & 3217 & 0,018 & 99 \\
\hline 44,1 & 6,8844 & 0,1039 & 0,3833 & 0,0057 & 0,98 & 2092 & 0,026 & 2097 & 0,013 & 2099 & 0,021 & 100 \\
\hline 45,1 & 10,4155 & 0,1524 & 0,4634 & 0,0067 & 0,99 & 2454 & 0,029 & 2472 & 0,013 & 2490 & 0,022 & 99 \\
\hline 46,1 & 4,4785 & 0,0650 & 0,3088 & 0,0043 & 0,97 & 1735 & 0,021 & 1727 & 0,012 & 1740 & 0,022 & 100 \\
\hline 47,1 & 4,4702 & 0,0644 & 0,3024 & 0,0042 & 0,97 & 1703 & 0,021 & 1725 & 0,012 & 1745 & 0,022 & 98 \\
\hline 48,1 & 7,2541 & 0,1036 & 0,3928 & 0,0055 & 0,98 & 2136 & 0,025 & 2143 & 0,013 & 2146 & 0,021 & 100 \\
\hline 49,1 & 7,8891 & 0,1031 & 0,4129 & 0,0030 & 0,55 & 2228 & 0,014 & 2218 & 0,012 & 2196 & 0,015 & 101 \\
\hline
\end{tabular}


Tabela 1. Continuação

\begin{tabular}{|c|c|c|c|c|c|c|c|c|c|c|c|c|}
\hline \multirow[b]{2}{*}{ Ponto } & \multicolumn{5}{|c|}{ Razões isotópicas } & \multicolumn{6}{|c|}{ Idades (Ma) } & \multirow[b]{2}{*}{ Concord. } \\
\hline & $\begin{array}{c}207 / \\
235\end{array}$ & $\begin{array}{c}\text { Erro } \\
1 \Sigma\end{array}$ & $\begin{array}{c}206 / \\
238\end{array}$ & $\begin{array}{c}\text { Erro } \\
1 \Sigma\end{array}$ & $\begin{array}{l}\text { Erro } \\
\text { Corr. }\end{array}$ & $\begin{array}{c}\text { T206/ } \\
238\end{array}$ & $\begin{array}{c}\text { Erro } \\
1 \Sigma\end{array}$ & $\begin{array}{c}\text { T207/ } \\
235\end{array}$ & $\begin{array}{c}\text { Erro } \\
1 \Sigma\end{array}$ & $\begin{array}{c}\text { T207/ } \\
206\end{array}$ & $\begin{array}{c}\text { Erro } \\
1 \Sigma\end{array}$ & \\
\hline 1,1 & 7,8494 & 0,0906 & 0,4081 & 0,0067 & 0,99 & 2206 & 0,031 & 2214 & 0,010 & 2208 & 0,039 & 100 \\
\hline 2,1 & 7,0325 & 0,0686 & 0,3844 & 0,0059 & 0,99 & 2097 & 0,028 & 2116 & 0,009 & 2126 & 0,039 & 99 \\
\hline 2,2 & 6,9367 & 0,0680 & 0,3799 & 0,0059 & 0,99 & 2076 & 0,027 & 2103 & 0,009 & 2129 & 0,039 & 98 \\
\hline 3,1 & 7,0587 & 0,0754 & 0,3895 & 0,0061 & 0,99 & 2121 & 0,028 & 2119 & 0,009 & 2145 & 0,039 & 99 \\
\hline 4,1 & 7,0756 & 0,0706 & 0,3836 & 0,0060 & 0,99 & 2093 & 0,028 & 2121 & 0,009 & 2147 & 0,038 & 98 \\
\hline 5,1 & 6,7038 & 0,0649 & 0,3778 & 0,0058 & 0,99 & 2066 & 0,027 & 2073 & 0,009 & 2076 & 0,038 & 100 \\
\hline 6,1 & 30,0957 & 0,2928 & 0,6996 & 0,0108 & 0,99 & 3419 & 0,041 & 3490 & 0,010 & 3533 & 0,037 & 97 \\
\hline 6,2 & 30,3966 & 0,2936 & 0,7079 & 0,0110 & 0,99 & 3450 & 0,041 & 3500 & 0,009 & 3535 & 0,037 & 98 \\
\hline 7,1 & 7,0396 & 0,0684 & 0,3866 & 0,0060 & 0,99 & 2107 & 0,028 & 2116 & 0,009 & 2130 & 0,038 & 99 \\
\hline 7,2 & 6,8319 & 0,0661 & 0,3734 & 0,0058 & 0,99 & 2045 & 0,027 & 2090 & 0,009 & 2138 & 0,038 & 96 \\
\hline 8,1 & 8,8262 & 0,1722 & 0,4154 & 0,0088 & 0,99 & 2240 & 0,040 & 2320 & 0,018 & 2413 & 0,039 & 93 \\
\hline 9,1 & 7,4175 & 0,0726 & 0,3922 & 0,0062 & 0,99 & 2133 & 0,028 & 2163 & 0,009 & 2189 & 0,038 & 97 \\
\hline 10,1 & 6,9787 & 0,0677 & 0,3794 & 0,0059 & 0,99 & 2073 & 0,028 & 2109 & 0,009 & 2148 & 0,038 & 97 \\
\hline 11,1 & 6,3214 & 0,1214 & 0,3585 & 0,0031 & 0,45 & 1975 & 0,015 & 2021 & 0,017 & 2067 & 0,018 & 96 \\
\hline 12,1 & 6,7717 & 0,1296 & 0,3737 & 0,0032 & 0,45 & 2047 & 0,015 & 2082 & 0,017 & 2119 & 0,018 & 97 \\
\hline 13,1 & 3,8520 & 0,0763 & 0,2795 & 0,0026 & 0,47 & 1589 & 0,013 & 1604 & 0,016 & 1607 & 0,022 & 99 \\
\hline 14,1 & 17,6256 & 0,3518 & 0,5746 & 0,0049 & 0,43 & 2927 & 0,020 & 2970 & 0,019 & 3020 & 0,019 & 97 \\
\hline 15,1 & 7,2826 & 0,1389 & 0,3944 & 0,0034 & 0,45 & 2143 & 0,016 & 2147 & 0,017 & 2153 & 0,018 & 100 \\
\hline 16,1 & 7,0896 & 0,1350 & 0,3853 & 0,0033 & 0,45 & 2101 & 0,015 & 2123 & 0,017 & 2151 & 0,018 & 98 \\
\hline 17,1 & 7,1166 & 0,1361 & 0,3896 & 0,0035 & 0,46 & 2121 & 0,016 & 2126 & 0,017 & 2115 & 0,018 & 100 \\
\hline 18,1 & 6,2152 & 0,1217 & 0,3506 & 0,0035 & 0,51 & 1937 & 0,017 & 2007 & 0,017 & 2087 & 0,018 & 93 \\
\hline 19,1 & 7,0767 & 0,1342 & 0,3845 & 0,0033 & 0,46 & 2097 & 0,015 & 2121 & 0,017 & 2146 & 0,018 & 98 \\
\hline 20,1 & 20,3234 & 0,3830 & 0,6200 & 0,0053 & 0,45 & 3110 & 0,021 & 3107 & 0,018 & 3116 & 0,016 & 100 \\
\hline 21,1 & 7,2188 & 0,1362 & 0,3922 & 0,0034 & 0,46 & 2133 & 0,016 & 2139 & 0,017 & 2144 & 0,018 & 100 \\
\hline 22,1 & 14,2688 & 0,2706 & 0,5238 & 0,0044 & 0,45 & 2715 & 0,019 & 2768 & 0,018 & 2792 & 0,017 & 97 \\
\hline 23,1 & 7,3655 & 0,1383 & 0,3979 & 0,0034 & 0,46 & 2160 & 0,016 & 2157 & 0,017 & 2153 & 0,018 & 100 \\
\hline 24,1 & 3,7475 & 0,0462 & 0,2766 & 0,0011 & 0,31 & 1574 & 0,005 & 1582 & 0,010 & 1595 & 0,020 & 99 \\
\hline 25,1 & 19,2400 & 0,2322 & 0,5822 & 0,0030 & 0,43 & 2958 & 0,012 & 3054 & 0,012 & 3126 & 0,015 & 95 \\
\hline 26,1 & 7,5229 & 0,0840 & 0,4000 & 0,0012 & 0,28 & 2169 & 0,006 & 2176 & 0,010 & 2179 & 0,016 & 100 \\
\hline 27,1 & 12,7886 & 0,1448 & 0,5088 & 0,0015 & 0,27 & 2651 & 0,007 & 2664 & 0,011 & 2684 & 0,016 & 99 \\
\hline 28,1 & 20,4174 & 0,2290 & 0,6206 & 0,0020 & 0,28 & 3112 & 0,008 & 3111 & 0,011 & 3117 & 0,015 & 100 \\
\hline 28,2 & 20,6124 & 0,2579 & 0,6218 & 0,0041 & 0,53 & 3117 & 0,016 & 3121 & 0,012 & 3115 & 0,015 & 100 \\
\hline 29,1 & 6,1979 & 0,0751 & 0,3639 & 0,0018 & 0,41 & 2001 & 0,009 & 2004 & 0,011 & 1993 & 0,017 & 100 \\
\hline 30,1 & 4,7328 & 0,0537 & 0,3181 & 0,0010 & 0,28 & 1780 & 0,005 & 1773 & 0,009 & 1789 & 0,017 & 100 \\
\hline 31,1 & 7,0639 & 0,0773 & 0,3833 & 0,0008 & 0,19 & 2092 & 0,004 & 2120 & 0,010 & 2144 & 0,016 & 98 \\
\hline 32,1 & 7,0199 & 0,0824 & 0,3860 & 0,0014 & 0,31 & 2104 & 0,006 & 2114 & 0,010 & 2154 & 0,017 & 98 \\
\hline 33,1 & 7,5332 & 0,0941 & 0,3961 & 0,0019 & 0,38 & 2151 & 0,009 & 2177 & 0,011 & 2203 & 0,018 & 98 \\
\hline 34,1 & 18,1009 & 0,2047 & 0,5924 & 0,0015 & 0,22 & 2999 & 0,006 & 2995 & 0,011 & 3033 & 0,015 & 99 \\
\hline 35,1 & 6,6722 & 0,0738 & 0,3640 & 0,0010 & 0,25 & 2001 & 0,005 & 2069 & 0,010 & 2140 & 0,016 & 94 \\
\hline 36,1 & 14,7759 & 0,2129 & 0,5460 & 0,0075 & 0,96 & 2808 & 0,031 & 2801 & 0,014 & 2811 & 0,020 & 100 \\
\hline 37,1 & 7,5861 & 0,1091 & 0,4033 & 0,0056 & 0,97 & 2184 & 0,026 & 2183 & 0,013 & 2189 & 0,021 & 100 \\
\hline 38,1 & 7,1047 & 0,1038 & 0,3900 & 0,0055 & 0,96 & 2123 & 0,025 & 2125 & 0,013 & 2128 & 0,021 & 100 \\
\hline 39,1 & 4,7895 & 0,0717 & 0,3192 & 0,0045 & 0,94 & 1786 & 0,022 & 1783 & 0,013 & 1794 & 0,022 & 100 \\
\hline 40,1 & 4,1544 & 0,0600 & 0,2962 & 0,0041 & 0,97 & 1672 & 0,021 & 1665 & 0,012 & 1658 & 0,022 & 101 \\
\hline 41,1 & 6,9214 & 0,1096 & 0,3848 & 0,0060 & 0,98 & 2099 & 0,028 & 2101 & 0,014 & 2090 & 0,021 & 100 \\
\hline 42,1 & 8,7241 & 0,1256 & 0,4330 & 0,0060 & 0,97 & 2319 & 0,027 & 2310 & 0,013 & 2290 & 0,021 & 101 \\
\hline 43,1 & 22,5020 & 0,3258 & 0,6354 & 0,0089 & 0,97 & 3171 & 0,035 & 3206 & 0,014 & 3217 & 0,018 & 99 \\
\hline 44,1 & 6,8844 & 0,1039 & 0,3833 & 0,0057 & 0,98 & 2092 & 0,026 & 2097 & 0,013 & 2099 & 0,021 & 100 \\
\hline 45,1 & 10,4155 & 0,1524 & 0,4634 & 0,0067 & 0,99 & 2454 & 0,029 & 2472 & 0,013 & 2490 & 0,022 & 99 \\
\hline 46,1 & 4,4785 & 0,0650 & 0,3088 & 0,0043 & 0,97 & 1735 & 0,021 & 1727 & 0,012 & 1740 & 0,022 & 100 \\
\hline 47,1 & 4,4702 & 0,0644 & 0,3024 & 0,0042 & 0,97 & 1703 & 0,021 & 1725 & 0,012 & 1745 & 0,022 & 98 \\
\hline 48,1 & 7,2541 & 0,1036 & 0,3928 & 0,0055 & 0,98 & 2136 & 0,025 & 2143 & 0,013 & 2146 & 0,021 & 100 \\
\hline 49,1 & 7,8891 & 0,1031 & 0,4129 & 0,0030 & 0,55 & 2228 & 0,014 & 2218 & 0,012 & 2196 & 0,015 & 101 \\
\hline
\end{tabular}


Tabela 1. Continuação

\begin{tabular}{|c|c|c|c|c|c|c|c|c|c|c|c|c|}
\hline \multirow[b]{2}{*}{ Ponto } & \multicolumn{5}{|c|}{ Razões isotópicas } & \multicolumn{6}{|c|}{ Idades (Ma) } & \multirow[b]{2}{*}{ Concord. } \\
\hline & $\begin{array}{c}207 / \\
235\end{array}$ & $\begin{array}{c}\text { Erro } \\
1 \Sigma\end{array}$ & $\begin{array}{c}206 / \\
238\end{array}$ & $\begin{array}{c}\text { Erro } \\
1 \Sigma\end{array}$ & $\begin{array}{l}\text { Erro } \\
\text { Corr. }\end{array}$ & $\begin{array}{c}\text { T206/ } \\
238\end{array}$ & $\begin{array}{c}\text { Erro } \\
1 \Sigma\end{array}$ & $\begin{array}{c}\text { T207/ } \\
235\end{array}$ & $\begin{array}{c}\text { Erro } \\
1 \Sigma\end{array}$ & $\begin{array}{c}\text { T207/ } \\
206\end{array}$ & $\begin{array}{c}\text { Erro } \\
1 \Sigma\end{array}$ & \\
\hline 50,1 & 12,4398 & 0,1526 & 0,4904 & 0,0026 & 0,43 & 2572 & 0,011 & 2638 & 0,011 & 2691 & 0,014 & 96 \\
\hline 51,1 & 7,2715 & 0,0897 & 0,3947 & 0,0022 & 0,45 & 2145 & 0,010 & 2145 & 0,011 & 2154 & 0,014 & 100 \\
\hline 52,1 & 7,5390 & 0,0920 & 0,4007 & 0,0021 & 0,43 & 2172 & 0,010 & 2178 & 0,011 & 2183 & 0,014 & 100 \\
\hline 53,1 & 7,1630 & 0,0875 & 0,3869 & 0,0021 & 0,44 & 2108 & 0,010 & 2132 & 0,011 & 2149 & 0,014 & 98 \\
\hline 54,1 & 6,8421 & 0,0835 & 0,3777 & 0,0020 & 0,43 & 2065 & 0,009 & 2091 & 0,011 & 2115 & 0,014 & 98 \\
\hline 55,1 & 7,7360 & 0,0950 & 0,4116 & 0,0023 & 0,45 & 2222 & 0,010 & 2201 & 0,011 & 2181 & 0,014 & 102 \\
\hline 56,1 & 6,3181 & 0,0772 & 0,3675 & 0,0020 & 0,44 & 2018 & 0,009 & 2021 & 0,011 & 2026 & 0,014 & 100 \\
\hline 56,2 & 6,2738 & 0,0762 & 0,3651 & 0,0019 & 0,43 & 2006 & 0,009 & 2015 & 0,011 & 2034 & 0,014 & 99 \\
\hline 57,1 & 11,5447 & 0,2691 & 0,4885 & 0,0076 & 0,66 & 2564 & 0,033 & 2568 & 0,022 & 2565 & 0,019 & 100 \\
\hline 58,1 & 7,3391 & 0,0898 & 0,3946 & 0,0021 & 0,44 & 2144 & 0,010 & 2154 & 0,011 & 2148 & 0,014 & 100 \\
\hline 59,1 & 7,3281 & 0,0897 & 0,3956 & 0,0021 & 0,44 & 2149 & 0,010 & 2152 & 0,011 & 2157 & 0,014 & 100 \\
\hline 59,2 & 7,6246 & 0,2262 & 0,4044 & 0,0072 & 0,60 & 2189 & 0,033 & 2188 & 0,026 & 2184 & 0,025 & 100 \\
\hline 60,1 & 10,9589 & 0,3261 & 0,4796 & 0,0086 & 0,60 & 2526 & 0,037 & 2520 & 0,027 & 2537 & 0,025 & 100 \\
\hline 61,1 & 6,9374 & 0,2032 & 0,3852 & 0,0067 & 0,60 & 2100 & 0,031 & 2103 & 0,026 & 2107 & 0,025 & 100 \\
\hline 62,1 & 9,6325 & 0,2837 & 0,4517 & 0,0081 & 0,61 & 2403 & 0,036 & 2400 & 0,027 & 2410 & 0,025 & 100 \\
\hline 63,1 & 14,8762 & 0,4335 & 0,5425 & 0,0095 & 0,60 & 2794 & 0,040 & 2807 & 0,027 & 2827 & 0,024 & 99 \\
\hline 64,1 & 6,6892 & 0,1961 & 0,3777 & 0,0067 & 0,61 & 2066 & 0,031 & 2071 & 0,026 & 2056 & 0,025 & 100 \\
\hline 65,1 & 7,4130 & 0,2156 & 0,3972 & 0,0070 & 0,60 & 2156 & 0,032 & 2163 & 0,026 & 2150 & 0,025 & 100 \\
\hline 66,1 & 7,3254 & 0,2129 & 0,3979 & 0,0071 & 0,61 & 2159 & 0,032 & 2152 & 0,026 & 2152 & 0,025 & 100 \\
\hline 67,1 & 7,1171 & 0,2054 & 0,3918 & 0,0068 & 0,61 & 2131 & 0,032 & 2126 & 0,025 & 2106 & 0,025 & 101 \\
\hline 68,1 & 12,9782 & 0,3734 & 0,5165 & 0,0090 & 0,61 & 2684 & 0,038 & 2678 & 0,027 & 2676 & 0,024 & 100 \\
\hline 69,1 & 7,3380 & 0,2106 & 0,3954 & 0,0069 & 0,61 & 2148 & 0,032 & 2153 & 0,025 & 2158 & 0,025 & 100 \\
\hline 70,1 & 16,8706 & 0,4834 & 0,5626 & 0,0098 & 0,61 & 2877 & 0,040 & 2928 & 0,027 & 2968 & 0,023 & 97 \\
\hline 71,1 & 14,7710 & 0,4210 & 0,5495 & 0,0096 & 0,61 & 2823 & 0,040 & 2801 & 0,027 & 2785 & 0,024 & 101 \\
\hline 72,1 & 6,8490 & 0,1408 & 0,3822 & 0,0073 & 0,93 & 2087 & 0,034 & 2092 & 0,018 & 2092 & 0,007 & 100 \\
\hline 73,1 & 7,0731 & 0,1458 & 0,3894 & 0,0075 & 0,94 & 2120 & 0,035 & 2121 & 0,018 & 2120 & 0,006 & 100 \\
\hline 74,1 & 13,6440 & 0,2802 & 0,5254 & 0,0101 & 0,93 & 2722 & 0,043 & 2725 & 0,019 & 2734 & 0,005 & 100 \\
\hline 75,1 & 4,0721 & 0,0954 & 0,2958 & 0,0064 & 0,93 & 1670 & 0,032 & 1649 & 0,019 & 1641 & 0,011 & 102 \\
\hline 76,1 & 6,4383 & 0,1336 & 0,3721 & 0,0072 & 0,93 & 2039 & 0,034 & 2038 & 0,018 & 2043 & 0,006 & 100 \\
\hline 77,1 & 7,6956 & 0,1598 & 0,4047 & 0,0078 & 0,93 & 2191 & 0,036 & 2196 & 0,018 & 2181 & 0,006 & 100 \\
\hline 78,1 & 6,7652 & 0,1406 & 0,3756 & 0,0073 & 0,93 & 2056 & 0,034 & 2081 & 0,018 & 2107 & 0,006 & 98 \\
\hline 79,1 & 6,8056 & 0,1456 & 0,3667 & 0,0074 & 0,94 & 2014 & 0,035 & 2086 & 0,019 & 2177 & 0,006 & 93 \\
\hline 80,1 & 8,1646 & 0,1744 & 0,4201 & 0,0084 & 0,93 & 2261 & 0,038 & 2249 & 0,019 & 2229 & 0,007 & 101 \\
\hline 81,1 & 6,5853 & 0,1407 & 0,3613 & 0,0071 & 0,93 & 1988 & 0,034 & 2057 & 0,019 & 2125 & 0,008 & 94 \\
\hline 82,1 & 7,3399 & 0,1558 & 0,3953 & 0,0078 & 0,93 & 2148 & 0,036 & 2154 & 0,019 & 2146 & 0,007 & 100 \\
\hline 83,1 & 9,2416 & 0,1963 & 0,4295 & 0,0085 & 0,93 & 2304 & 0,038 & 2362 & 0,019 & 2408 & 0,007 & 96 \\
\hline 84,1 & 7,1107 & 0,1502 & 0,3908 & 0,0077 & 0,93 & 2127 & 0,036 & 2125 & 0,019 & 2119 & 0,006 & 100 \\
\hline
\end{tabular}

mais importantes dos sedimentos (Tab. 1, Fig. 4). Fontes paleoproterozoicas precoces e arqueanas também se destacam ( $29 \%$ da população), distribuídas sobre quatro períodos: 2,4 - 2,5 Ga; 2,7 - 2,8 Ga; 3,0 - 3,1 Ga; e 3,4 Ga. O zircão mais jovem mostrou uma idade ${ }^{207} \mathrm{~Pb} /{ }^{206} \mathrm{~Pb}$ de $1.595 \pm$ $20 \mathrm{Ma}$ (99\% concordante), considerada a idade máxima de deposição da Formação Resplandecente nesta região.

No Conglomerado Grão Mogol, foram analisados 115 pontos sobre 114 grãos de zircóes, os quais apresentaram idades $\mathrm{U}-\mathrm{Pb}$ sobre uma distribuição de tempo maior, variando de 1.052 a $3.426 \mathrm{Ma}$ (Tab. 2, Fig. 5).
De modo semelhante à unidade inferior, porém, predominam idades entre 1,96 a 2,20 Ga (44 grãos, ou $-38 \%$ da população), seguidas por idades arqueanas (24 grãos; $-21 \%$ da população) concentradas em quatro intervalos praticamente idênticos aos da Formação Resplandecente. Ambas devem representar as principais áreas fontes da sedimentação. Nessa amostra, foi observada uma população mais jovem, distribuída entre 1,38 e 1,48 Ma (11 grãos, $-10 \%$ da população), não observada no quartzito inferior. $\mathrm{O}$ zircão mais novo mostrou idade ${ }^{207} \mathrm{~Pb} /{ }^{206} \mathrm{~Pb}$ de $1.052 \pm 50 \mathrm{Ma}$ (9\% discordante), 
Idades U-Pb do conglomerado diamantífero de Grão Mogol

Tabela 2. Dados geocronológicos U-Pb obtidos em zircões detríticos do conglomerado da Formação Grão Mogol, na localidade homônima, Espinhaço Meridional

\begin{tabular}{|c|c|c|c|c|c|c|c|c|c|c|}
\hline \multirow[b]{2}{*}{ Ponto } & \multicolumn{5}{|c|}{ Razões isotópicas } & \multicolumn{4}{|c|}{ Idades (Ma) } & \multirow[b]{2}{*}{ Concord. } \\
\hline & $\begin{array}{c}207 / \\
235\end{array}$ & $\begin{array}{c}\text { Erro } \\
1 \Sigma\end{array}$ & $\begin{array}{c}206 / \\
238\end{array}$ & $\begin{array}{c}\text { Erro } \\
1 \Sigma\end{array}$ & $\begin{array}{l}\text { Erro } \\
\text { Corr. }\end{array}$ & $\begin{array}{c}\text { T207/ } \\
235\end{array}$ & $\begin{array}{c}\text { Erro } \\
1 \Sigma\end{array}$ & $\begin{array}{c}\text { T207/ } \\
206\end{array}$ & $\begin{array}{c}\text { Erro } \\
1 \Sigma\end{array}$ & \\
\hline 2,1 & 3,4879 & 0,0468 & 0,2641 & 0,0026 & 0,75 & 1,960 & 0,017 & 2,039 & 0,034 & 96 \\
\hline 3,1 & 6,9608 & 0,0938 & 0,3721 & 0,0037 & 0,74 & 1,511 & 0,013 & 1,566 & 0,037 & 97 \\
\hline 4,1 & 21,3323 & 0,2850 & 0,6206 & 0,0062 & 0,75 & 2,039 & 0,017 & 2,181 & 0,034 & 94 \\
\hline 5,1 & 3,6381 & 0,0491 & 0,2689 & 0,0027 & 0,74 & 3,112 & 0,025 & 3,190 & 0,030 & 98 \\
\hline 6,1 & 3,5328 & 0,0474 & 0,2636 & 0,0026 & 0,74 & 1,535 & 0,014 & 1,607 & 0,036 & 96 \\
\hline 7,1 & 2,9504 & 0,0393 & 0,2363 & 0,0024 & 0,75 & 1,508 & 0,013 & 1,576 & 0,036 & 96 \\
\hline 8,1 & 17,6220 & 0,2407 & 0,5874 & 0,0062 & 0,77 & 1,367 & 0,012 & 1,462 & 0,037 & 94 \\
\hline 9,1 & 12,1844 & 0,1613 & 0,4921 & 0,0049 & 0,75 & 2,979 & 0,025 & 2,982 & 0,031 & 100 \\
\hline 10,1 & 12,4776 & 0,1706 & 0,5076 & 0,0054 & 0,77 & 2,580 & 0,021 & 2,657 & 0,033 & 97 \\
\hline 11,1 & 3,6984 & 0,0492 & 0,2746 & 0,0028 & 0,75 & 2,646 & 0,023 & 2,654 & 0,033 & 100 \\
\hline 12,1 & 4,9796 & 0,0685 & 0,3262 & 0,0035 & 0,77 & 1,564 & 0,014 & 1,598 & 0,036 & 98 \\
\hline 13,1 & 6,0390 & 0,0798 & 0,3616 & 0,0036 & 0,76 & 1,820 & 0,017 & 1,828 & 0,034 & 100 \\
\hline 14,1 & 3,1539 & 0,0228 & 0,2521 & 0,0023 & 0,99 & 1,990 & 0,017 & 1,992 & 0,034 & 100 \\
\hline 15,1 & 6,8638 & 0,0417 & 0,3842 & 0,0033 & 0,99 & 1,449 & 0,012 & 1,454 & 0,023 & 100 \\
\hline 16,1 & 4,5670 & 0,0278 & 0,3019 & 0,0026 & 0,99 & 2,096 & 0,015 & 2,099 & 0,019 & 100 \\
\hline 17,1 & 14,6753 & 0,0928 & 0,5280 & 0,0045 & 0,99 & 1,701 & 0,013 & 1,809 & 0,020 & 94 \\
\hline 18,1 & 2,9732 & 0,0173 & 0,2395 & 0,0020 & 0,99 & 2,733 & 0,019 & 2,856 & 0,019 & 96 \\
\hline 19,1 & 6,4397 & 0,0402 & 0,3655 & 0,0032 & 0,99 & 1,384 & 0,010 & 1,449 & 0,021 & 96 \\
\hline 20,1 & 6,3984 & 0,0366 & 0,3615 & 0,0030 & 0,99 & 2,008 & 0,015 & 2,075 & 0,019 & 97 \\
\hline 21,1 & 7,3941 & 0,1279 & 0,3996 & 0,0070 & 0,99 & 1,989 & 0,014 & 2,079 & 0,019 & 96 \\
\hline 22,1 & 3,7589 & 0,0223 & 0,2779 & 0,0024 & 0,99 & 2,167 & 0,032 & 2,157 & 0,020 & 100 \\
\hline 23,1 & 4,6036 & 0,0287 & 0,3118 & 0,0027 & 0,99 & 1,581 & 0,012 & 1,602 & 0,021 & 99 \\
\hline 24,1 & 11,8846 & 0,0776 & 0,4786 & 0,0043 & 0,99 & 1,750 & 0,013 & 1,774 & 0,020 & 99 \\
\hline 25,1 & 3,6792 & 0,0234 & 0,2737 & 0,0024 & 0,99 & 2,521 & 0,019 & 2,666 & 0,019 & 95 \\
\hline 26,1 & 11,8286 & 0,0780 & 0,4696 & 0,0041 & 0,99 & 1,559 & 0,012 & 1,590 & 0,021 & 98 \\
\hline 27,1 & 13,0272 & 0,1259 & 0,5009 & 0,0038 & 0,78 & 2,482 & 0,018 & 2,675 & 0,019 & 93 \\
\hline 28,1 & 4,3687 & 0,0455 & 0,3026 & 0,0025 & 0,79 & 2,617 & 0,016 & 2,739 & 0,020 & 96 \\
\hline 29,1 & 6,9193 & 0,0672 & 0,3742 & 0,0029 & 0,79 & 1,704 & 0,012 & 1,745 & 0,022 & 98 \\
\hline 31,1 & 6,8683 & 0,0676 & 0,3747 & 0,0029 & 0,78 & 2,049 & 0,014 & 2,160 & 0,021 & 95 \\
\hline 32,1 & 7,2566 & 0,0701 & 0,3847 & 0,0029 & 0,79 & 2,051 & 0,014 & 2,148 & 0,021 & 96 \\
\hline 33,1 & 4,0308 & 0,0465 & 0,2691 & 0,0023 & 0,75 & 2,098 & 0,014 & 2,196 & 0,021 & 96 \\
\hline 34,1 & 3,4191 & 0,0337 & 0,2538 & 0,0020 & 0,78 & 1,536 & 0,012 & 1,774 & 0,022 & 87 \\
\hline 36,1 & 7,1921 & 0,0691 & 0,3880 & 0,0030 & 0,79 & 1,458 & 0,010 & 1,588 & 0,022 & 92 \\
\hline 37,1 & 6,5131 & 0,0646 & 0,3730 & 0,0030 & 0,81 & 2,114 & 0,014 & 2,165 & 0,021 & 98 \\
\hline 38,1 & 7,0847 & 0,0685 & 0,3834 & 0,0029 & 0,79 & 2,043 & 0,014 & 2,069 & 0,021 & 99 \\
\hline 39,1 & 3,4473 & 0,0349 & 0,2654 & 0,0022 & 0,82 & 2,092 & 0,014 & 2,167 & 0,021 & 97 \\
\hline 40,1 & 4,7604 & 0,0297 & 0,3159 & 0,0042 & 0,99 & 1,518 & 0,011 & 1,540 & 0,022 & 99 \\
\hline 41,1 & 4,9718 & 0,0336 & 0,3240 & 0,0044 & 0,99 & 1,770 & 0,021 & 1,777 & 0,029 & 100 \\
\hline 42,1 & 6,4024 & 0,0389 & 0,3631 & 0,0049 & 0,99 & 1,809 & 0,021 & 1,805 & 0,029 & 100 \\
\hline 43,1 & 23,3682 & 0,2176 & 0,6529 & 0,0098 & 0,99 & 1,997 & 0,023 & 2,066 & 0,028 & 97 \\
\hline 44,1 & 7,1429 & 0,0460 & 0,3903 & 0,0053 & 0,99 & 3,240 & 0,038 & 3,225 & 0,025 & 100 \\
\hline 45,1 & 17,0151 & 0,1052 & 0,5769 & 0,0078 & 0,99 & 2,124 & 0,025 & 2,134 & 0,028 & 100 \\
\hline 46,1 & 12,0524 & 0,0732 & 0,4909 & 0,0066 & 0,99 & 2,936 & 0,032 & 2,939 & 0,026 & 100 \\
\hline 47,1 & 6,7175 & 0,0405 & 0,3763 & 0,0051 & 0,99 & 2,574 & 0,028 & 2,631 & 0,027 & 98 \\
\hline 48,1 & 3,5471 & 0,0234 & 0,2688 & 0,0037 & 0,99 & 2,059 & 0,024 & 2,087 & 0,028 & 99 \\
\hline 49,1 & 4,5181 & 0,0286 & 0,3042 & 0,0041 & 0,99 & 1,535 & 0,019 & 1,542 & 0,030 & 100 \\
\hline 50,1 & 3,0702 & 0,0195 & 0,2461 & 0,0033 & 0,99 & 1,712 & 0,020 & 1,755 & 0,029 & 98 \\
\hline 51,1 & 13,0983 & 0,0803 & 0,5099 & 0,0069 & 0,99 & 1,419 & 0,017 & 1,438 & 0,031 & 99 \\
\hline 52,1 & 4,7122 & 0,0299 & 0,3154 & 0,0043 & 0,99 & 2,656 & 0,030 & 2,716 & 0,027 & 98 \\
\hline 53,1 & 17,7804 & 0,0444 & 0,5848 & 0,0067 & 0,99 & 1,767 & 0,021 & 1,775 & 0,028 & 100 \\
\hline 54,1 & 6,1429 & 0,1194 & 0,3630 & 0,0078 & 0,99 & 2,968 & 0,027 & 2,982 & 0,014 & 100 \\
\hline 55,1 & 4,7792 & 0,0124 & 0,3190 & 0,0036 & 0,99 & 1,997 & 0,037 & 2,004 & 0,016 & 100 \\
\hline 55,2 & 4,8538 & 0,0204 & 0,3203 & 0,0038 & 0,99 & 1,785 & 0,018 & 1,787 & 0,016 & 100 \\
\hline 56,1 & 7,2113 & 0,0181 & 0,3897 & 0,0045 & 0,99 & 1,791 & 0,019 & 1,783 & 0,016 & 100 \\
\hline 58,1 & 2,0041 & 0,0265 & 0,1605 & 0,0023 & 0,99 & 2,121 & 0,021 & 2,153 & 0,016 & 99 \\
\hline 59,1 & 6,2353 & 0,0159 & 0,3558 & 0,0041 & 0,99 & 0,959 & 0,013 & 1,052 & 0,050 & 91 \\
\hline
\end{tabular}


Tabela 2. Continuação

\begin{tabular}{|c|c|c|c|c|c|c|c|c|c|c|}
\hline \multirow[b]{2}{*}{ Ponto } & \multicolumn{5}{|c|}{ Razões isotópicas } & \multicolumn{4}{|c|}{ Idades (Ma) } & \multirow[b]{2}{*}{ Concord. } \\
\hline & $\begin{array}{c}207 / \\
235\end{array}$ & $\begin{array}{c}\text { Erro } \\
1 \Sigma\end{array}$ & $\begin{array}{c}206 / \\
238\end{array}$ & $\begin{array}{c}\text { Erro } \\
1 \Sigma\end{array}$ & $\begin{array}{l}\text { Erro } \\
\text { Corr. }\end{array}$ & $\begin{array}{c}\text { T207/ } \\
235\end{array}$ & $\begin{array}{c}\text { Erro } \\
1 \Sigma\end{array}$ & $\begin{array}{c}\text { T207/ } \\
206\end{array}$ & $\begin{array}{c}\text { Erro } \\
1 \Sigma\end{array}$ & \\
\hline 60,1 & 6,5600 & 0,0277 & 0,3612 & 0,0043 & 0,99 & 1,962 & 0,020 & 2,059 & 0,015 & 95 \\
\hline 61,1 & 10,6973 & 0,0770 & 0,4497 & 0,0058 & 0,99 & 1,988 & 0,020 & 2,124 & 0,015 & 94 \\
\hline 63,1 & 3,6547 & 0,0102 & 0,2732 & 0,0032 & 0,99 & 2,394 & 0,026 & 2,584 & 0,015 & 93 \\
\hline 64,1 & 12,7855 & 0,0289 & 0,4996 & 0,0058 & 0,99 & 1,557 & 0,016 & 1,563 & 0,017 & 100 \\
\hline 65,1 & 6,7368 & 0,1190 & 0,3756 & 0,0058 & 0,88 & 2,612 & 0,025 & 2,695 & 0,015 & 97 \\
\hline 66,1 & 19,3704 & 0,3455 & 0,6068 & 0,0094 & 0,87 & 2,056 & 0,027 & 2,106 & 0,018 & 98 \\
\hline 67,1 & 7,0079 & 0,1251 & 0,3723 & 0,0057 & 0,86 & 3,057 & 0,038 & 3,073 & 0,016 & 100 \\
\hline 68,1 & 3,0906 & 0,0540 & 0,2454 & 0,0038 & 0,87 & 2,040 & 0,027 & 2,171 & 0,018 & 94 \\
\hline 69,1 & 14,3042 & 0,2512 & 0,5254 & 0,0081 & 0,88 & 1,414 & 0,019 & 1,466 & 0,020 & 97 \\
\hline 70,1 & 3,6219 & 0,0688 & 0,2689 & 0,0044 & 0,87 & 2,722 & 0,034 & 2,808 & 0,017 & 97 \\
\hline 71,1 & 28,4064 & 0,4940 & 0,7014 & 0,0107 & 0,88 & 1,535 & 0,023 & 1,591 & 0,020 & 97 \\
\hline 72,1 & 3,2585 & 0,0569 & 0,2523 & 0,0039 & 0,87 & 3,426 & 0,040 & 3,443 & 0,017 & 100 \\
\hline 73,1 & 4,5326 & 0,0829 & 0,3044 & 0,0050 & 0,89 & 1,450 & 0,020 & 1,531 & 0,019 & 95 \\
\hline 74,1 & 7,3988 & 0,1978 & 0,3981 & 0,0108 & 0,99 & 1,713 & 0,024 & 1,770 & 0,018 & 97 \\
\hline 75,1 & 3,7085 & 0,0652 & 0,2779 & 0,0043 & 0,87 & 2,160 & 0,050 & 2,157 & 0,020 & 100 \\
\hline 76,1 & 6,9537 & 0,1218 & 0,3862 & 0,0059 & 0,88 & 1,581 & 0,021 & 1,563 & 0,019 & 101 \\
\hline 77,1 & 7,0775 & 0,1227 & 0,3895 & 0,0059 & 0,88 & 2,105 & 0,028 & 2,105 & 0,018 & 100 \\
\hline 78,1 & 6,7972 & 0,1412 & 0,3765 & 0,0050 & 0,64 & 2,120 & 0,028 & 2,129 & 0,018 & 100 \\
\hline 79,1 & 7,0722 & 0,1464 & 0,3893 & 0,0051 & 0,63 & 2,060 & 0,023 & 2,112 & 0,021 & 98 \\
\hline 80,1 & 7,1414 & 0,1476 & 0,3892 & 0,0051 & 0,63 & 2,120 & 0,024 & 2,126 & 0,021 & 100 \\
\hline 81,1 & 6,9898 & 0,1446 & 0,3871 & 0,0051 & 0,63 & 2,119 & 0,024 & 2,127 & 0,021 & 100 \\
\hline 82,1 & 3,9484 & 0,0871 & 0,2855 & 0,0044 & 0,70 & 2,109 & 0,024 & 2,114 & 0,021 & 100 \\
\hline 83,1 & 6,7919 & 0,1405 & 0,3830 & 0,0050 & 0,64 & 1,619 & 0,022 & 1,612 & 0,023 & 100 \\
\hline 84,1 & 4,6294 & 0,0954 & 0,3087 & 0,0040 & 0,64 & 2,090 & 0,023 & 2,081 & 0,021 & 100 \\
\hline 85,1 & 4,5726 & 0,0966 & 0,3097 & 0,0042 & 0,64 & 1,734 & 0,020 & 1,776 & 0,021 & 98 \\
\hline 86,1 & 4,1807 & 0,0876 & 0,2875 & 0,0039 & 0,65 & 1,739 & 0,021 & 1,734 & 0,023 & 100 \\
\hline 87,1 & 12,8291 & 0,2638 & 0,5114 & 0,0067 & 0,64 & 1,629 & 0,020 & 1,742 & 0,022 & 94 \\
\hline 88,1 & 3,7872 & 0,0780 & 0,2794 & 0,0037 & 0,64 & 2,663 & 0,028 & 2,674 & 0,020 & 100 \\
\hline 89,1 & 6,6479 & 0,1370 & 0,3796 & 0,0050 & 0,64 & 1,589 & 0,019 & 1,596 & 0,022 & 100 \\
\hline 90,1 & 3,2568 & 0,0677 & 0,2570 & 0,0035 & 0,65 & 2,074 & 0,024 & 2,050 & 0,021 & 101 \\
\hline 91,1 & 7,1942 & 0,2308 & 0,3932 & 0,0066 & 0,53 & 1,474 & 0,018 & 1,470 & 0,023 & 100 \\
\hline 92,1 & 3,6753 & 0,1176 & 0,2739 & 0,0046 & 0,53 & 2,138 & 0,031 & 2,136 & 0,028 & 100 \\
\hline 93,1 & 7,3946 & 0,2361 & 0,3993 & 0,0068 & 0,53 & 1,561 & 0,023 & 1,583 & 0,031 & 99 \\
\hline 93,2 & 7,5072 & 0,2393 & 0,4000 & 0,0068 & 0,53 & 2,166 & 0,031 & 2,165 & 0,028 & 100 \\
\hline 94,1 & 3,3045 & 0,1052 & 0,2623 & 0,0045 & 0,54 & 2,169 & 0,031 & 2,160 & 0,028 & 100 \\
\hline 95,1 & 4,6915 & 0,1487 & 0,3152 & 0,0053 & 0,53 & 1,502 & 0,023 & 1,472 & 0,031 & 102 \\
\hline 96,1 & 7,5212 & 0,2376 & 0,4007 & 0,0067 & 0,53 & 1,766 & 0,026 & 1,763 & 0,029 & 100 \\
\hline 97,1 & 3,3071 & 0,1042 & 0,2586 & 0,0043 & 0,53 & 2,172 & 0,031 & 2,163 & 0,028 & 100 \\
\hline 98,1 & 7,3233 & 0,2301 & 0,3969 & 0,0067 & 0,54 & 1,483 & 0,022 & 1,487 & 0,031 & 100 \\
\hline 99,1 & 7,1493 & 0,2244 & 0,3985 & 0,0067 & 0,54 & 2,155 & 0,031 & 2,148 & 0,028 & 100 \\
\hline 100,1 & 12,7161 & 0,3985 & 0,5088 & 0,0086 & 0,54 & 2,162 & 0,031 & 2,110 & 0,028 & 102 \\
\hline 101,1 & 7,8656 & 0,2452 & 0,4098 & 0,0069 & 0,54 & 2,652 & 0,036 & 2,688 & 0,027 & 99 \\
\hline 102,1 & 6,1023 & 0,1930 & 0,3484 & 0,0062 & 0,57 & 2,214 & 0,031 & 2,187 & 0,028 & 101 \\
\hline 103,1 & 3,5860 & 0,0591 & 0,2718 & 0,0042 & 0,95 & 1,927 & 0,030 & 2,057 & 0,028 & 94 \\
\hline 104,1 & 7,4768 & 0,1243 & 0,3989 & 0,0063 & 0,95 & 1,550 & 0,021 & 1,535 & 0,026 & 101 \\
\hline 105,1 & 7,3951 & 0,1221 & 0,4021 & 0,0063 & 0,95 & 2,164 & 0,029 & 2,158 & 0,024 & 100 \\
\hline 106,1 & 6,9867 & 0,1143 & 0,3935 & 0,0062 & 0,96 & 2,179 & 0,029 & 2,126 & 0,024 & 102 \\
\hline 107,1 & 13,9377 & 0,2284 & 0,5314 & 0,0083 & 0,96 & 2,139 & 0,028 & 2,079 & 0,024 & 103 \\
\hline 108,1 & 7,4488 & 0,1234 & 0,4001 & 0,0063 & 0,96 & 2,747 & 0,035 & 2,752 & 0,023 & 100 \\
\hline 109,1 & 3,6099 & 0,0594 & 0,2755 & 0,0044 & 0,96 & 2,170 & 0,029 & 2,142 & 0,024 & 101 \\
\hline 110,1 & 11,9967 & 0,1967 & 0,4914 & 0,0077 & 0,96 & 1,569 & 0,022 & 1,545 & 0,026 & 101 \\
\hline 111,1 & 3,4988 & 0,0575 & 0,2679 & 0,0042 & 0,96 & 2,577 & 0,033 & 2,633 & 0,023 & 98 \\
\hline 112,1 & 21,3089 & 0,4380 & 0,6307 & 0,0112 & 0,87 & 1,530 & 0,021 & 1,533 & 0,026 & 100 \\
\hline 112,2 & 20,2037 & 0,3297 & 0,6190 & 0,0098 & 0,97 & 3,152 & 0,044 & 3,152 & 0,022 & 100 \\
\hline 113,1 & 7,4851 & 0,1235 & 0,4104 & 0,0065 & 0,96 & 3,106 & 0,039 & 3,108 & 0,021 & 100 \\
\hline 114,1 & 3,0528 & 0,0507 & 0,2458 & 0,0039 & 0,96 & 2,217 & 0,030 & 2,132 & 0,024 & 104 \\
\hline
\end{tabular}




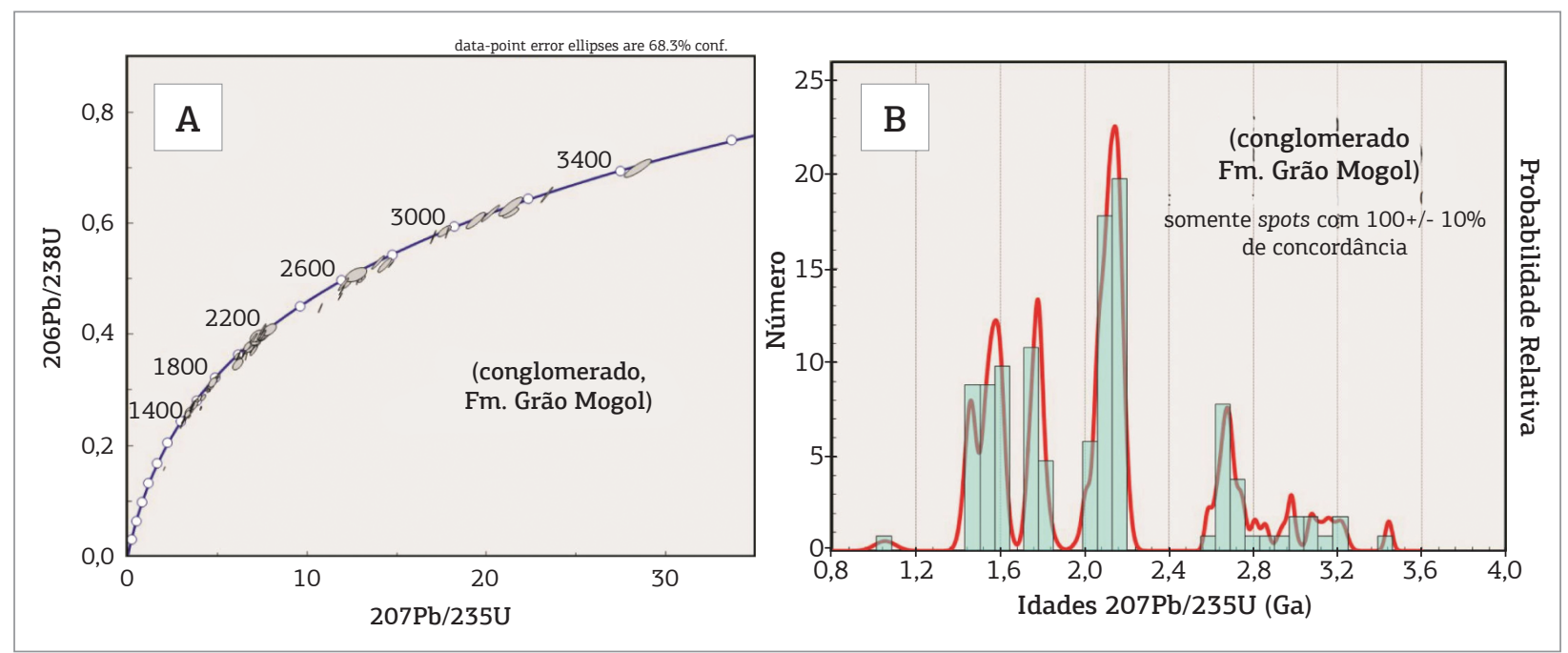

Figura 5. Diagrama U-Pb concórdia (A) e histograma de probabilidade relativa (B) dos zircões detríticos amostrados no conglomerado basal da Formação Grão Mogol.

que pode ser admitida como a idade máxima de sedimentação da Formação Grão Mogol.

\section{DISCUSSÕES}

Depósitos secundários de diamantes constituem objeto preferencial de lavra em diversas áreas de ocorrência das formaçóes Sopa-Brumadinho, em Diamantina, e Grão Mogol, na localidade homônima. Diamantes provavelmente estão presentes também nos depósitos neoproterozoicos da Formação Jequitaí (cratônica) e sua equivalente na Faixa Araçuaí, Formação Serra do Catuni, do Grupo Macaúbas, o que se deduz a partir da existência de depósitos cenozoicos mineralizados sobrepostos ou proximais a essas formaçôes (Moraes \& Guimarães 1930, Paiva Filho \& Ponçano 1972, Martins 2006, Chaves et al. 2010a). As unidades inferiores às anteriormente citadas parecem ser estéreis; de fato, sobre extensas áreas de exposiçốes das formaçôes São João da Chapada/Bandeirinha (Diamantina), Resplandecente (Itacambira e Grão Mogol) e Duas Barras (BocaiúvaItacambira) nunca foram reportadas quaisquer ocorrências diamantíferas em sedimentos recentes adjacentes.

As idades máximas dessas unidades são razoavelmente caracterizadas pela geocronologia U-Pb de zircôes detríticos (Fig. 6). Nessa figura são apresentados os seis principais intervalos de idades de zircôes dos metassedimentos do Supergrupo Espinhaço e do Grupo Macaúbas, conforme os dados obtidos, contextualizados a outras dataçóes disponíveis (Rodrigues 2008, Martins et al. 2008, Chemale Jr. et al. 2011, 2012, Babinski et al. 2012). Como raciocínio lógico, uma dessas populações de zircóes deve fazer parte da mesma rocha fonte (magmática) primária dos diamantes, que presumivelmente constitui-se, a julgar por centenas de depósitos assemelhados a nível mundial, de kimberlitos ou lamproítos. No limite inferior, tais fontes magmáticas devem ser iguais ou mais antigas que $1.050 \mathrm{Ma}$, idade do grão de zircão detrítico mais jovem recuperado neste estudo, em Grão Mogol. Quanto ao limite superior, constitui uma incógnita, uma vez que os diamantes costumam ser continuamente reciclados no decorrer do registro geológico (Sutherland 1977).

Abre-se, assim, um extenso leque de possibilidades a ser investigado. Em princípio, pode-se considerar que o tipo petrológico original e a idade dessa enigmática fonte primária sejam aproximadamente os mesmos para toda a Bacia Espinhaço, tendo em vista que as fontes secundárias se encontram em domínio geotectônico similar, relacionadas aos sucessivos picos distensionais da bacia rifte, bem como apresentam ambientes deposicionais muito semelhantes. Associando-se inicialmente as formaçôes Sopa-Brumadinho e Grão Mogol pela presença de zircóes detríticos, a fonte diamantífera primária deve ser limitada a dois intervalos de idades: entre 1,05 - 1,35 Ga e 1,70 - 1,80 Ga (Fig. 6). Quando se incluem em tal linha de raciocínio as formaçóes Jequitaí e Serra do Catuni, ambas diamantíferas e provavelmente alimentadas pelas mesmas fontes primárias, esses dois períodos de idades destacados também aparecem. É presumível que idades arqueanas (também presentes) possam ser descartadas, pois, a nível mundial, é muito restrita a ocorrência de kimberlitos ou lamproítos dessa época.

Entretanto, como as formaçôes Bandeirinha e São João da Chapada não são diamantíferas, o período entre 1,7 - 1,8 Ga, definido a partir dos hematita filitos (magmáticos) intercalados principalmente na última unidade, e cujo protólito é alvo de muitas discussões (Dussin 1994, 


\begin{tabular}{|c|c|c|c|c|c|c|c|}
\hline & Idades Ga & $1,05-1,35$ & $1,45-1,60$ & $1,65-1,80$ & $2,00-2,20$ & $2,65-2,85$ & $>3,00$ \\
\hline 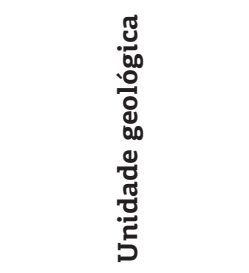 & 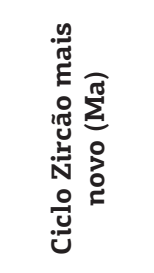 & 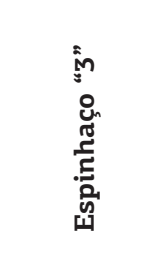 & 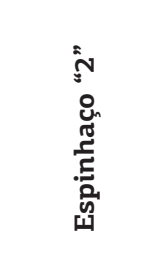 & 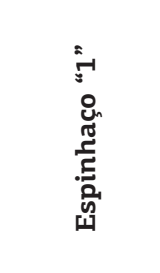 & 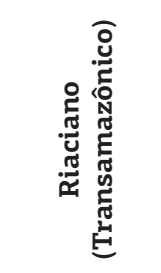 & 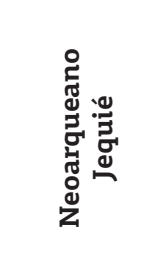 & 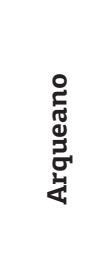 \\
\hline Jequitaí $^{1}$ & $833+/-22$ & & & & & & \\
\hline Serra do Catuni ${ }^{2}$ & $933+/-08$ & & & & & & \\
\hline Duas Barras $^{2}$ & $900+/-21$ & & & & & & \\
\hline Matão ${ }^{3}$ & $1161+/-50$ & & & & & & \\
\hline Grão Mogo ${ }^{1}$ & $1052+/-50$ & & & & & & \\
\hline Conselheiro Mata ${ }^{4}$ & $1328+/-12$ & & & & & & \\
\hline $\begin{array}{l}\text { Resplandecente/ } \\
\text { Galho do Miguel }\end{array}$ & $1595+/-20$ & & & & & & \\
\hline Sopa-Brumadinho ${ }^{4}$ & $1080+/-16$ & & & & & & \\
\hline $\begin{array}{l}\text { S. João da } \\
\text { Chapada }^{4}\end{array}$ & $1703+/-12$ & & & & & & \\
\hline Bandeirinha $^{4}$ & & & & & & & \\
\hline
\end{tabular}

Figura 6. Intervalos principais de idades e ciclos geotectônicos relacionados, dos zircões detríticos encontrados em unidades estratigráficas siliciclásticas do Supergrupo Espinhaço e do Grupo Macaúbas na Serra do Espinhaço em suas porções Central e Meridional. Dados, excetuando as formações Resplandecente e Grão Mogol, conforme Rodrigues (2008) $)^{1}$, Babinski et al. (2012) $)^{2}$, Martins et al. (2008) $)^{3}$ e Chemale Jr. et al. (2012)

Hagedorn 2004), pode ser excluído como portador de mineralização primária. As idades Espinhaço "2", compreendidas entre 1,45 - 1,60 Ga, registradas em zircóes detríticos no presente trabalho em Grão Mogol, também são identificadas no Espinhaço Baiano e se baseiam em rochas vulcânicas básicas (não diamantíferas) do Grupo Pajeú, com 1,57 Ga (Danderfer et al. 2009).

A prevalência de zircôes detríticos sobre um longo lapso de tempo, praticamente contínuo entre 1,05 e 1,35 Ga (Espinhaço “3” ou "Grenvilleano”), embora a identificação e a localização de suas fontes ainda náo estejam perfeitamente estabelecidas, pode explicar um período extenso de erupçóes e/ou intrusóes magmáticas, as quais poderiam ser a fonte da mineralização tanto dos conglomerados de Gráo Mogol como daquelas da Formação Sopa-Brumadinho (em Diamantina). Corrobora para a assertiva da mineralização associada a este intervalo de idade o fato de que a única rocha primária confirmada como diamantífera na Serra do Espinhaço, e com datação disponível, a metaintrusão Salvador-1 (Barra do Mendes, Bahia), foi datada em 1.152 Ma (Rb/Sr em flogopita - Pereira \& Fuck 2005, Chaves et al. 2010b).

\section{CONCLUSÃO}

A partir da constatação de idades grenvilleanas no Supergrupo Espinhaço, agora também em Grão Mogol, abrese um extenso campo de investigaçóes a respeito dos tempos de sedimentação e magmatismo dessa megassequência, bem como da evolução do rifte em seu conjunto no tempo e no espaço, e da possibilidade de fontes diamantíferas associadas. A hipótese de uma origem autóctone grenvilleana se antagoniza com as ideias clássicas que consideravam uma área-fonte distal para a mineralização diamantífera, no Cráton São Francisco (Pflug 1965, Chaves 1997, Chaves et al. 2001), ou associada ao agora chamado "Espinhaço I" (Almeida-Abreu 1993, Hagedorn 2004). As idades mais antigas encontradas correspondem a magmatismos paleoproterozoicos e arqueanos, bem conhecidos em metassedimentos da regiáo e adjacências (Sano et al. 2002, Noce et al. 2005, Martins et al. 2008, Pimentel et al. 2011, Chemale Jr. et al. 2012).

A idade de sedimentaçáo estabelecida para a Formação Grão Mogol, inferior a 1,05 Ga, é muito semelhante àquela obtida para a Formação Sopa-Brumadinho na região de Diamantina $(<1,08 \mathrm{Ga})$. Destaca-se, porém, que as unidades quartzíticas de origem eólica, pertencentes às formaçôes Resplandecente, em Grão Mogol, e Galho do Miguel, em Diamantina, estratigraficamente correlatas, também apresentam zircóes mais novos semelhantes, com idades de 1,57 e 1,50 Ga, respectivamente. De tal maneira, constitui um aspecto a ser compreendido o fato de que tais unidades ocupem posiçóes estratigráficas distintas relativamente aos conglomerados diamantíferos (formações Grão Mogol e Sopa-Brumadinho) nestas localidades. No Espinhaço Meridional, as sequências eólicas estão sobrepostas aos conglomerados, enquanto no Espinhaço Central as rochas 
diamantíferas ocupam posição de topo, o que denota as condiçôes paleoclimáticas áridas a semiáridas da bacia prevalecentes no período de geração desse conjunto sedimentar.

Outra conclusão importante a respeito da estratigrafia regional é que se atestando idades semelhantes (dadas pelos zircôes mais novos) entre as formaçóes Matão/Água Preta e Grão Mogol, mesmo que tenham sido propostas com base em correlaçóes estratigráficas distintas (conforme Fig. 3), o termo Grão Mogol deve ser abandonado tendo em vista a prioridade por antiguidade do termo Formação Matão. Tal assunto, entretanto, deve constituir a temática de futuro trabalho, de cunho estratigráfico.

Considerando-se que na região de Diamantina a Formação Galho do Miguel possui cerca de $1.000 \mathrm{~m}$ de espessura, e em Grão Mogol a Formação Resplandecente pelo menos $300 \mathrm{~m}$, bem como as posiçóes estratigráficas específicas das rochas diamantíferas nesses locais, provavelmente ocorreu mais do que um evento mineralizante na bacia Espinhaço no período Grenvilleano (1,35 - 1,05 Ga). A favor desta hipótese, destaca-se a notável discordância entre os conglomerados diamantíferos e os metarenitos em Grão Mogol, indicando hiato de tempo significativo entre ambos, pois os sedimentos eólicos já estariam diagenizados na ocasião de sedimentação dos primeiros. Em termos prospectivos, a extensa área de embasamento que ocorre logo a oeste do Espinhaço em Grão Mogol e ao longo do Espinhaço Central, embora arrasada geomorfologicamente, poderia preservar as raízes das intrusóes que constituíram a fonte dos conglomerados diamantíferos.

\section{AGRADECIMENTOS}

O autor Mario Luiz de Sá Carneiro Chaves agradece à Fundação de Apoio à Pesquisa do Estado de Minas Gerais (FAPEMIG) pelos recursos de auxílio à pesquisa (Proc. CRA-APQ-01255-09), que permitiram a obtenção das dataçóes geocronológicas relatadas, e ao Conselho Nacional de Desenvolvimento Científico e Tecnológico (CNPq) pela concessáo de bolsa de produtividade em pesquisa.

\section{REFERÊNCIAS}

Alkmim F.F. \& Martins-Neto M.M. 2012. Proterozoic first-order sedimentary sequences of the São Francisco craton, eastern Brazil. Marine and Petroleum Geology, 33:127-139.

Almeida-Abreu P.A. 1993. A evolução geodinâmica da Serra do Espinhaço Meridional, Minas Gerais, Brasil. Tese de Doutorado, Albert-Ludwig Universität, Freiburg, 150 p.

Almeida-Abreu P.A. \& Renger F.E. 2007. Stratigraphy and facies of the southern Serra do Espinhaço, Minas Gerais, Brazil. Zeitschrift der Deutschen Geologischen Gesellschaft, 158:9-29.

Babinski M., Pedrosa-Soares A.C., Trindade R.I.F., Martins M, Noce C.M., Liu D. 2012. Neoproterozoic glacial deposits from the Araçuaí orogen, Brazil: age, provenance and correlations with the São Francisco craton and West Congo belt. Gondwana Research, 21(2-3):451-465

Brito-Neves B.B., Kawashita K., Cordani U.G., Delhal J. 1979. A evolução geocronológica da Serra do Espinhaço, dados novos e integração. Revista Brasileira de Geociências, 9:71-85.

Chaves M.L.S.C. 1997. Geologia e mineralogia do diamante da Serra do Espinhaço em Minas Gerais. Tese de Doutorado, Instituto de Geociências, Universidade de São Paulo, São Paulo, 289 p.

Chaves M.L.S.C., Benitez L., Andrade K.W. 2009. Morro da Pedra Rica, Grão Mogol, MG - primeira jazida de diamantes minerada em rocha no mundo. In: Winge M. (ed). Sítios geológicos e paleontológicos do Brasil. Brasília, CPRM, v.2, p. 213-252.

Chaves M.L.S.C., Guimarães J.T., Andrade K.W. 2010a. Litofácies glaciomarinhas na Formação Jequitaí: possíveis implicações na redistribuição de diamantes a oeste da Serra do Espinhaço (MG). Revista Brasileira de Geociências, 40(4):516-526.

Chaves M.L.S.C., Karfunkel J., Addad J. 1999. Geologia da região diamantífera de Grão Mogol, Minas Gerais. Geociências, 18:129-155.
Chaves M.L.S.C., Karfunkel J., Hoover D.B. 2001. Diamonds from the Espinhaço Range (Minas Gerais, Brazil) and their redistribution through the geologic record. Journal of South America Earth Sciences, 14:277-289.

Chaves M.L.S.C., Pedreira A.J., Benitez L. 2010b. A intrusão diamantífera Salvador-1 (Barra do Mendes, BA). In: SBG, Simpósio Brasileiro de Geologia do Diamante, 5, Tibagi, Anais, p. 79-80.

Chemale Jr. F., Dussin I.A., Alkmim F.F., Martins M.S., Queiroga G., Armstrong R., Santos M.N. 2012. Unravelling a Proterozoic basin history through detrital zircon geochronology: the case of the Espinhaço Supergroup, Minas Gerais, Brazil. Gondwana Research, 22:200-206

Chemale Jr. F., Dussin I.A., Martins M., Santos M.N. 2011. Nova abordagem tectono-estratigráfica do Supergrupo Espinhaço em sua porção meridional (MG). Geonomos, 19(2):173-179.

Danderfer A., De Waele B., Pedreira A.A.J., Nalini Jr. H.A. 2009. New geochronological constraints on the geological evolution of Espinhaço basin within the São Francisco craton - Brazil. Precambrian Research, 170:116-128.

Dossin I.A., Dossin T.M., Chaves M.L.S.C. 1990. Compartimentação estratigráfica do Supergrupo Espinhaço em Minas Gerais: os grupos Diamantina e Conselheiro Mata. Revista Brasileira de Geociências, 20:178-186.

Dussin T.M. 1994. Associations plutono-volcaniques de l'Espinhaço Méridional: un exemple d'évolution de la croûte protérozoïque. Tese de Doutorado, Université d'Orleans, Orleans, 177 p.

Hagedorn M.G. 2004. Contexto geotectônico da Serra do Espinhaço e domínios adjacentes a leste (Minas Gerais) com ênfase em aspectos geoquímicos e geocronológicos. Tese de Doutorado, Instituto de Geociências e Ciências Exatas, Universidade Estadual Paulista, Rio Claro, $215 \mathrm{p}$. 
Heineck C.A., Leite C.A.S., Silva M.A., Vieira V.S. 2003. Mapa geológico do Estado de Minas Gerais, Escala 1:1.000.000. Belo Horizonte, Convênio COMIG/CPRM, 1 folha.

Helmreichen V. 1846. Über das geognostische Vorkommen der Diamanten und ihre Gewinnungsmethoden auf der Serra do GrãoMogór in der Provinz Minas-Geraes in Brasilien. Viena, Braumüller \& Seidel, $74 \mathrm{p}$

Karfunkel B. \& Karfunkel J. 1976. Geologia da Serra do Espinhaço no norte de Minas Gerais (ltacambira - Botumirim). In: SBG, Congresso Brasileiro de Geologia, 29, Ouro Preto, Anais, v.2, p.169-178.

Karfunkel B. \& Karfunkel J. 1977. Fazielle Entwicklung der mittleren Espinhaço-Zone mit besonderer Berücksichtigung des TillitProblems (Minas Gerais, Brasilien). Geologisches Jahrbuch, 24:3-91.

Ludwig K.R. 2001. User's manual for Isoplot/Ex Version 2.49. A geochronological toolkit for Microsoft Excel. Berkeley, USA, Berkeley Geochronological Center, 55 p.

Machado N., Schrank A., Abreu F.R., Knauer L.G., Almeida-Abreu P.A. 1989. Resultados preliminares da geocronologia U-Pb na Serra do Espinhaço Meridional. In: SBG, Simpósio de Geologia de Minas Gerais, 5, Diamantina, Anais, p. 171-174.

Martins M.S. 2006. Geologia dos diamantes e carbonados da bacia do Rio Macaúbas (MG). Tese de Doutorado, Instituto de Geociências, Universidade Federal de Minas Gerais, Belo Horizonte, 231 p.

Martins M., Karfunkel J., Noce C.M., Babinsky M., Pedrosa-Soares A.C., Sial A.N., Liu D. 2008. A sequência pré-glacial do grupo Macaúbas na área-tipo e o registro da abertura do rifte Araçuaí. Revista Brasileira de Geociências, 38(4):761-772.

Martins-Neto M.A. 1998. O Supergrupo Espinhaço em Minas Gerais: registro de uma bacia rifte-sag do Paleo/Mesoproterozóico. Revista Brasileira de Geociências, 48(2):151-168.

Martins-Neto M.A. 2000. Tectonics and sedimentation in a paleo/ mesoproterozoic rift-sag basin (Espinhaço basin, southeastern Brazil). Precambrian Research, 103(3-4):147-173.

Martins-Neto M.A., Pedrosa-Soares A.C., Lima S.A.A. 2001 Tectono-sedimentary evolution of sedimentary basins from the Late Paleoproterozoic to Late Neoproterozoic in the São Francisco craton and Araçuaí fold belt, eastern Brazil. Sedimentary Geology, 141-142:343-370

Moraes L.J. \& Guimarães D. 1930. Geologia da região diamantífera do norte de Minas Gerais. Anais da Academia Brasileira de Ciências, 2(2):153-186.

Noce C.M., Zuccheti M., Baltazar O.F., Armstrong R., Dantas E., Renger F.E., Lobato L.M. 2005. Age of felsic volcanism and the role of ancient continental crust in the evolution of the Neoarchean Rio das Velhas Greenstone belt (Quadrilátero Ferrífero, Brazil): U-Pb zircon dating of volcaniclastic graywackes. Precambrian Research, 141(1-2):67-82.
Paiva Filho A. \& Ponçano W. 1972. Mapa geológico preliminar da região de Jequitaí, Estado de Minas Gerais. In: SBG, Congresso Brasileiro de Geologia, 26, Anais, 1:95-102.

Pereira R.S. \& Fuck R.A. 2005. Archean nuclei and the distribution of kimberlite and related rocks in the São Francisco Craton, Brazil. Revista Brasileira de Geociências, 35:93-104

Pflug R. 1965. A geologia da parte meridional da Serra do Espinhaço e zonas adjacentes, Minas Gerais. Boletim da Divisão de Geologia e Mineralogia, 226:1-55.

Pimentel M.M., Rodrigues J.B., DellaGiustina M.E.S., Junges S., Matteini M., Armstrong R. 2011. The tectonic evolution of the Neoproterozoic Brasília Belt, central Brazil, based on SHRIMP and LA-ICPMS U-Pb sedimentary provenance data: a review. Journal of South American Earth Sciences, 31(4):345-357.

Rodrigues J.B. 2008. Proveniência de sedimentos dos grupos Canastra, Ibiá, Vazante e Bambuí: um estudo de zircões detríticos e idades modelo Sm-Nd. Tese de Doutorado, Instituto de Geociências, Universidade de Brasília, Brasília, 141 p.

Sano Y., Yokoshi R., Chaves M.L., Ozima M. 2002. Ion microprobe $\mathrm{Pb}-\mathrm{Pb}$ dating of carbonado, polycristalline diamond. Precambrian Research, 113(1):155-168

Schobbenhaus C. 1993. O Proterozóico Médio no Brasil com ênfase à região centro-leste. Tese de Doutorado, Albert-Ludwig Universität, Freiburg, $166 \mathrm{p}$.

Schobbenhaus C. 1996. As trafrogêneses superpostas Espinhaço e Santo Onofre, Estado da Bahia: revisão e novas propostas. Revista Brasileira de Geociências, 26(4):265-276.

Schöll W.U. \& Fogaça A.C.C. 1979. Estratigrafia da Serra do Espinhaço em Diamantina (MG). In: SBG, Simpósio de Geologia de Minas Gerais, 1, Diamantina, Atas, p. 55-73.

Sutherland D.G. 1977. The transport and sorting of diamonds by fluvial and marine processes. Economic Geology, 77:1613-1620.

Uhlein A. 1991. Transição cráton-faixa dobrada: um exemplo do Cráton do São Francisco e da Faixa Araçuaí (ciclo Brasiliano) no Estado de Minas Gerais. Tese de Doutorado. Instituto de Geociências, Universidade de São Paulo, São Paulo, 295 p.

Uhlein A. \& Chaves M.L.S.C. 2001. O Supergrupo Espinhaço em Minas Gerais e Bahia: correlações estratigráficas, conglomerados diamantíferos e evolução geodinâmica. Revista Brasileira de Geociências, 31:433-444

Arquivo digital disponível on-line no site www.sbgeo.org.br 